\title{
A Climatology of Extratropical Cyclones Leading to Extreme Weather Events over Central and Eastern North America
}

\author{
Alicia M. BENTLEy \\ I.M. Systems Group, Inc., and NOAA/NWS/NCEP/EMC, College Park, Maryland \\ LANCE F. BOSART AND DANIEL KEYSER \\ Department of Atmospheric and Environmental Sciences, University at Albany, State University \\ of New York, Albany, New York
}

(Manuscript received 21 December 2018, in final form 6 February 2019)

\begin{abstract}
Cool-season extreme weather events (EWEs) (i.e., high-impact weather events that are societally disruptive, geographically widespread, exceptionally prolonged, and climatologically infrequent) are typically associated with strong extratropical cyclones (ECs). The opportunity to investigate the genesis locations, tracks, and frequencies of ECs leading to EWEs over central and eastern North America and compare them to those of ordinary ECs forming over and traversing the same region motivates this study. ECs leading to EWEs are separated from ordinary ECs according to the magnitude, areal extent, and duration of their 925-hPa standardized wind speed anomalies in the $0.5^{\circ}$ NCEP CFSR dataset. This separation allows for the construction of an October-March 1979-2016 climatology of ECs leading to EWEs over central and eastern North America. The climatology of ECs leading to EWEs over central and eastern North America reveals that these ECs typically form in the lee of the Rocky Mountains, over the south-central United States, and along the east coast of North America at latitudes equatorward of the typical genesis locations of ordinary ECs. ECs leading to EWEs exhibit equatorward-shifted tracks relative to ordinary ECs, likely associated with an equatorward shift in the position of the subtropical or polar-front jet. ECs leading to EWEs form most frequently in November and March, when the seasonal alignment of baroclinic and diabatic forcings is maximized. Similar to ordinary ECs, the genesis locations, tracks, and frequencies of ECs leading to EWEs are partially determined by the states of the Pacific-North American pattern and North Atlantic Oscillation.
\end{abstract}

\section{Introduction}

Extratropical cyclones (ECs) play a major role in determining day-to-day weather conditions in the middle latitudes during the cool season. Particularly strong ECs, such as the infamous Superstorm of March 1993 (SS93) (e.g., Huo et al. 1995; Kocin et al. 1995; Uccellini et al. 1995; Alfonso and Naranjo 1996; Bosart et al. 1996; Dickinson et al. 1997; SPC 1999), can have considerable socioeconomic impacts on the regions they traverse due to their frequent association with damaging winds and heavy precipitation (e.g., Salmon and Smith 1980; Gyakum 1983a,b; Uccellini et al. 1984, 1985; Hakim et al. 1995, 1996; Mailier et al. 2006; Dacre et al. 2012). Particularly strong ECs forming over and traversing

\footnotetext{
Corresponding author: Alicia M. Bentley, alicia.bentley@ noaa.gov
}

densely populated regions of central and eastern North America have the potential to lead to extreme weather events (EWEs), defined in the present study as highimpact weather events that are societally disruptive, geographically widespread, exceptionally prolonged, and climatologically infrequent. Figure 1 illustrates the mean sea level pressure (MSLP), 925-hPa winds, and 925-hPa standardized wind speed anomalies associated with SS93 at 0000 UTC 14 March 1993. The areal extent and magnitude of $925-\mathrm{hPa}$ standardized wind speed anomalies associated with SS93 in Fig. 1 are characteristic of the $925-\mathrm{hPa}$ standardized wind speed anomalies associated with SS93 throughout the majority of its 84-h life cycle (1200 UTC 12 March-0000 UTC 16 March 1993), suggesting that SS93 meets the definition of an EC leading to an EWE. This suggestion is supported by the first-place ranking of SS93 on the Northeast Snowfall Impact Scale (Kocin and Uccellini 2004), 


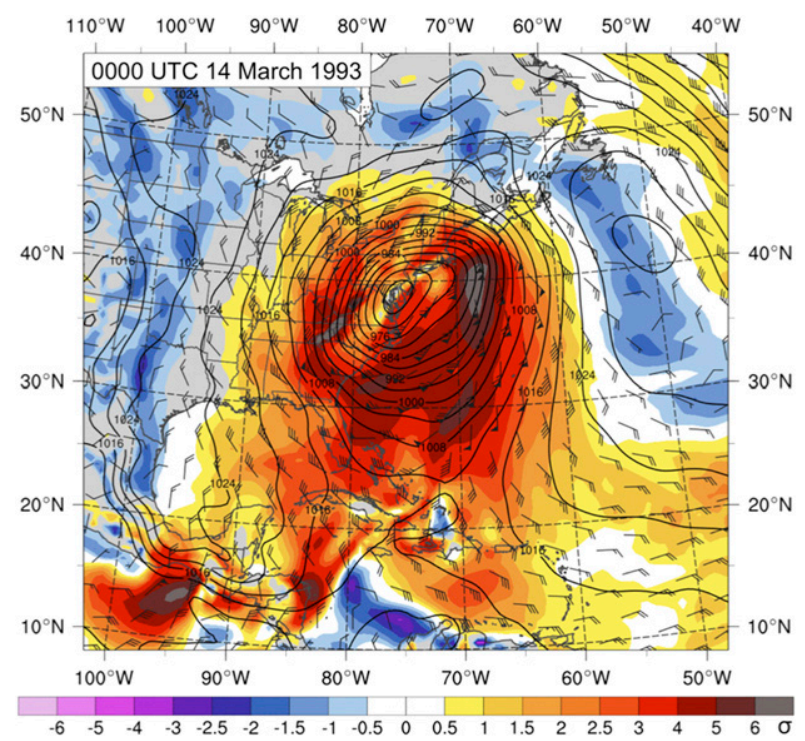

FIG. 1. Analysis showing MSLP (black contours, hPa), 925-hPa winds (flags and barbs, kt), and 925-hPa standardized wind speed anomalies (shaded, $\sigma$ ) associated with SS93 at 0000 UTC 14 March 1993 in the $0.5^{\circ}$ NCEP Climate Forecast System Reanalysis (CFSR) dataset.

which classifies SS93 as the highest-impact Northeast U.S. EC since 1950 (NCEI 2018).

ECs forming over and traversing central and eastern North America were extensively documented during the twentieth and early twenty-first centuries (Table 1). Early climatologies of North American ECs were painstakingly created using paper maps and hand analyses (e.g., Saucier 1949; Hurley 1954; Petterssen 1956; Klein 1957). The advent of reanalysis datasets during the late twentieth century allowed the meteorological community to construct comprehensive, longterm climatologies of ECs over central and eastern North America using high-resolution gridded datasets (e.g., Hoskins and Hodges 2002; Hodges et al. 2011; Tilinina et al. 2013; Grise et al. 2013). Despite differences in their construction, both early and recent climatologies of ECs over central and eastern North America (Table 1) reveal that these ECs typically form in the lee of the Rocky Mountains and along the east coast of North America before traversing the Great Lakes and western North Atlantic, respectively. ECs forming in the lee of the Rocky Mountains typically develop in response to vortex tube stretching occurring downstream of a mountain barrier (e.g., Petterssen 1956, section 13.5) in the presence of an upper-tropospheric trough (e.g., Palmén and Newton 1969; Bannon 1992; Davis 1997), whereas ECs forming along the east coast of North America typically develop in association with the semipermanent baroclinic zone created by the juxtaposition of the relatively warm waters of the Gulf Stream and relatively cold continental air moving off the eastern edge of North America (e.g., Sanders and Gyakum 1980). Surface fluxes of heat and moisture may also contribute to the formation and maintenance of ECs along the east coast of North America (e.g., Roebber 1989a; McTaggartCowan et al. 2017), often enhancing diabatic processes during the evolution of individual ECs (e.g., Atlas 1987; Uccellini et al. 1987; Davis and Emanuel 1988; Roebber 1989b, 1993).

In addition to forming more frequently over certain regions, ECs over central and eastern North America form more frequently during certain times of the year. Whittaker and Horn (1981) and Changnon et al. (1995) both determined that ECs over central and eastern North America form more frequently during the cool season (October-March) than during the warm season (April-September), with a seasonal peak in the frequency of EC formation during January-March. The frequent formation of ECs over central and eastern North America during the cool season is likely associated with the presence of relatively strong horizontal temperature gradients over these regions during October-March that are maximized during Northern Hemisphere winter. The frequent occurrence of rapidly deepening ECs along the east coast of North America during October-March (e.g., Sanders and Gyakum 1980) is also likely associated with the presence of relatively strong horizontal temperature gradients over the region during this period. The frequent occurrence of rapidly deepening ECs along the east coast of North America as opposed to in the lee of the Rocky Mountains suggests that a combination of baroclinic and diabatic processes may be required for rapid cyclogenesis to occur (e.g., Tracton 1973; Sanders and Gyakum 1980; Roebber 1984; Reed et al. 1988, 1992, 1993a,b; Reed and Simmons 1991; Kuo et al. 1996; Roebber and Schumann 2011). Studies investigating rapidly deepening ECs over the Kuroshio of the western North Pacific, another location where rapid cyclogenesis frequently occurs (Sanders and Gyakum 1980), have also suggested the importance of baroclinic and diabatic processes during the evolution of rapidly deepening ECs (e.g., Gyakum et al. 1992; Bullock and Gyakum 1993; Gyakum and Danielson 2000).

Despite the extensive documentation of ECs over central and eastern North America during the twentieth and early twenty-first centuries (Table 1), few studies have examined ECs leading to EWEs forming over and traversing the same region. A climatology of ECs leading to EWEs over central and eastern North America during October-March 1979-2016 will be constructed 
TABLE 1. Examples of climatologies that document ECs over the Northern Hemisphere, North America, the United States, and regions comprising central and eastern North America (i.e., Rocky Mountains, central United States, and east coast of North America). Climatologies are separated into regions according to the genesis location of ECs included in the climatology. The period of study and applicable reference are given for each climatology. An asterisk next to a reference indicates that the climatology exclusively identifies rapidly deepening ECs.

\begin{tabular}{|c|c|c|}
\hline Region & $\begin{array}{l}\text { Period of } \\
\text { study }\end{array}$ & Reference \\
\hline \multirow{7}{*}{$\begin{array}{l}\text { Northern } \\
\text { Hemisphere }\end{array}$} & 1899-1936 & Petterssen (1956) \\
\hline & 1899-1936 & Klein (1957) \\
\hline & 1979-2000 & Hoskins and Hodges (2002) \\
\hline & 1958-2001 & Wernli and Schwierz (2006) \\
\hline & 1979-2009 & Hodges et al. (2011) \\
\hline & 1950-2010 & Eichler and Gottschalck (2013) \\
\hline & 1979-2010 & Tilinina et al. (2013) \\
\hline \multirow[t]{8}{*}{ North America } & $1951-70$ & Reitan (1974) \\
\hline & 1976-79 & Sanders and Gyakum (1980)* \\
\hline & $1950-77$ & Zishka and Smith (1980) \\
\hline & $1958-77$ & Whittaker and Horn (1981) \\
\hline & $1976-82$ & Roebber (1984)* \\
\hline & $1950-93$ & Changnon et al. (1995) \\
\hline & 1971-2000 & Eichler and Higgins (2006) \\
\hline & 1982-2011 & Grise et al. (2013) \\
\hline \multirow[t]{2}{*}{ United States } & 1892-1912 & Bowie and Weightman (1914) \\
\hline & $1905-54$ & Hosler and Gamage (1956) \\
\hline \multirow[t]{4}{*}{ Rocky Mountains } & 1958 & Chung et al. (1976) \\
\hline & $1961-90$ & Bierly and Harrington (1995) \\
\hline & 1988-92 & Hutchinson (1995) \\
\hline & 1986-2001 & Thomas and Martin (2007) \\
\hline \multirow{4}{*}{$\begin{array}{l}\text { Central United } \\
\text { States }\end{array}$} & 1899-1939 & Saucier (1949) \\
\hline & 1920-29 & Hurley (1954) \\
\hline & $1950-74$ & Brennan and Smith (1978) \\
\hline & 1950-2000 & Changnon et al. (2008) \\
\hline \multirow{6}{*}{$\begin{array}{l}\text { East coast of } \\
\text { North America }\end{array}$} & 1929-39 & Miller (1946) \\
\hline & $1921-62$ & Mather et al. (1964) \\
\hline & 1964-73 & Colucci (1976) \\
\hline & 1885-1978 & Hayden (1981) \\
\hline & 1948, 1951-97 & Hirsch et al. (2001) \\
\hline & 1979-2004 & Colle et al. (2013) \\
\hline
\end{tabular}

in the present study in order to document the location and frequency of these high-impact weather events. Such a climatology will allow the genesis locations, tracks, and frequencies of ECs leading to EWEs to be compared to those of ordinary ECs over central and eastern North America, providing insight into the climatological differences between these two categories of ECs.

The remainder of this paper is organized as follows. The data and methodology used to identify ECs leading to EWEs over central and eastern North America are described in section 2. Section 3 contains a climatology of ECs leading to EWEs over central and eastern North America during October-March 1979-2016, as well as a comparison of the location and frequency of these ECs to the location and frequency of ordinary ECs forming over and traversing the same region during the same period. Results of this study are summarized and future work is proposed in section 4 .

\section{Data and methodology}

\section{a. Candidate ECs leading to EWEs}

Northern Hemisphere cyclone tracks [provided by B. A. Colle (Stony Brook University)] are identified during October-March 1979-2016 by applying the Hodges (1994, 1995) tracking algorithm to the MSLP field obtained from the $0.5^{\circ}$ NCEP Climate Forecast System Reanalysis (CFSR) dataset (Saha et al. 2010) using the methodology of Colle et al. (2013). The time of cyclone formation $\left(t_{0}\right)$ is defined as the first time a cyclone is identified using the Hodges $(1994,1995)$ tracking algorithm. The tendency for the Hodges $(1994,1995)$ tracking algorithm to delay the identification of cyclones by several hours and to underestimate the central MSLP value of the cyclones it identifies has been documented (P. J. Roebber 2019, personal communication), but these tendencies do not dramatically affect the identification of ECs leading to EWEs in the present study. As will be shown in section $2 b$, the identification of ECs leading to EWEs in the present study is not dependent on the characteristics of individual cyclones at times relative to $t_{0}$ nor the central MSLP value of individual cyclones during their life cycle.

To be included in a list of potential candidate ECs leading to EWEs over central and eastern North America $(N=2332)$, Northern Hemisphere cyclones are required to form over and traverse the region surrounding central and eastern North America between $t_{0}$ and $t_{0}+48 \mathrm{~h}$. Cyclones whose tracks correspond to tropical cyclones included in the International Best Track Archive for Climate Stewardship dataset (Knapp et al. 2010) are removed from the list of potential candidates $(N=12)$. Cyclones remaining in the list of potential candidates after the removal of tropical cyclones are considered candidate ECs leading to EWEs over central and eastern North America $(N=2320)$. A track map of the 2320 cyclones considered candidate ECs leading to EWEs over central and eastern North America, as well as the region over which they are required to form and traverse between $t_{0}$ and $t_{0}+48 \mathrm{~h}$, is shown in Fig. 2 .

\section{b. Identification of ECs leading to EWEs}

ECs leading to EWEs (i.e., high-impact weather events that are societally disruptive, geographically widespread, exceptionally prolonged, and climatologically infrequent) are identified as those ECs included in the list of 2320 candidates that exhibit the strongest 


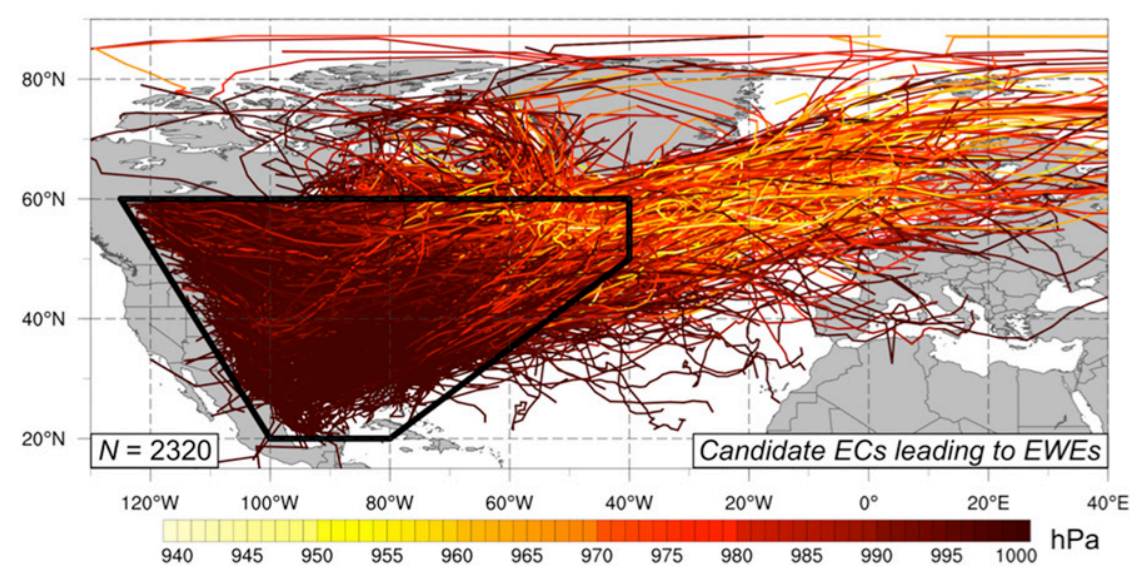

FIG. 2. Tracks of candidate ECs leading to EWEs over central and eastern North America during October-March 1979-2016, shaded according to their central MSLP value (hPa). The black polygon denotes the region over which candidate ECs leading to EWEs are required to form and traverse between $t_{0}$ and $t_{0}+48 \mathrm{~h}$.

lower-tropospheric winds within a large geographic area for the longest period of time. To assess the strength of the lower-tropospheric winds associated with candidate ECs leading to EWEs, area-averaged 925-hPa standardized wind speed anomalies are calculated with respect to a 1979-2009 climatology [constructed using the methodology of Brammer and Thorncroft (2015)] within $1200 \mathrm{~km}$ of each candidate during its life cycle. A radius of $1200 \mathrm{~km}$, equivalent to the maximum mean effective radius of Northern Hemisphere ECs (Rudeva and Gulev 2011), was selected to ensure that the region within which area-averaged $925-\mathrm{hPa}$ standardized wind speed anomalies are calculated is representative of the area affected by relatively large ECs. An example of the distribution and evolution of $925-\mathrm{hPa}$ standardized wind speed anomalies within $1200 \mathrm{~km}$ of SS93 is shown in Fig. 3. Area-averaged 925-hPa standardized wind speed anomalies within $1200 \mathrm{~km}$ of SS 93 are $<1 \sigma$ at 1200 UTC 12 March 1993 (Fig. 3a), increase to $>2 \sigma$ as SS93 matures and traverses the east coast of North America between 1200 UTC 13 March and 14 March 1993 (Figs. 3b,c), and decrease to $<1 \sigma$ as SS93 weakens near the southern tip of Greenland at 1200 UTC 15 March 1993 (Fig. 3d).

Candidate ECs leading to EWEs are separated into two categories, ordinary ECs and ECs leading to EWEs, based on the number of hours (if any) that each candidate attained an area-averaged $925-\mathrm{hPa}$ standardized wind speed anomaly $\geq 1 \sigma$. Figure 4 depicts the frequency distribution of candidate ECs leading to EWEs binned by the number of hours that each candidate attained an area-averaged $925-\mathrm{hPa}$ standardized wind speed anomaly $\geq 1 \sigma$. Figure 4 indicates that candidate ECs leading to EWEs that attained an area-averaged 925-hPa standardized wind speed anomaly $\geq 1 \sigma$ for $<36 \mathrm{~h}$ represent $95 \%$ of all candidates and are identified as ordinary ECs $(N=2202)$. Candidate ECs leading to EWEs that did not attain an area-averaged $925-\mathrm{hPa}$ standardized wind speed anomaly $\geq 1 \sigma$ (i.e., the 0 -h bin in Fig. 4) are included in this category. Candidate ECs leading to EWEs that attained an area-averaged $925-\mathrm{hPa}$ standardized wind speed anomaly $\geq 1 \sigma$ for $\geq 36 \mathrm{~h}$ represent the top $5 \%$ of all candidates (i.e., the tail of the distribution) and are identified as ECs leading to EWEs $(N=118)$. The right-skewed structure of the frequency distribution shown in Fig. 4 is similar to the rightskewed structure of the frequency distribution of 24-h EC deepening rates shown by Roebber (1984, his Fig. 3), with both ECs leading to EWEs and rapidly deepening ECs occurring in the tails of their respective distributions. A track map of the 118 cyclones identified as ECs leading to EWEs over central and eastern North America during October-March 1979-2016 is shown in Fig. 5. Noteworthy ECs leading to EWEs over central and eastern North America during October-March 1979-2016 include SS93 (e.g., Huo et al. 1995; Kocin et al. 1995; Uccellini et al. 1995; Bosart et al. 1996; Dickinson et al. 1997), the 9-11 November 1998 central U.S. cyclone (Iacopelli and Knox 2001), and the 26-27 October 2010 central U.S. cyclone (WPC 2010).

\section{Climatological results}

\section{a. Genesis locations}

Figure 6 compares the genesis densities of ordinary ECs and ECs leading to EWEs over central and eastern North America during October-March 1979-2016. Figure 6a reveals that ordinary ECs may develop almost 

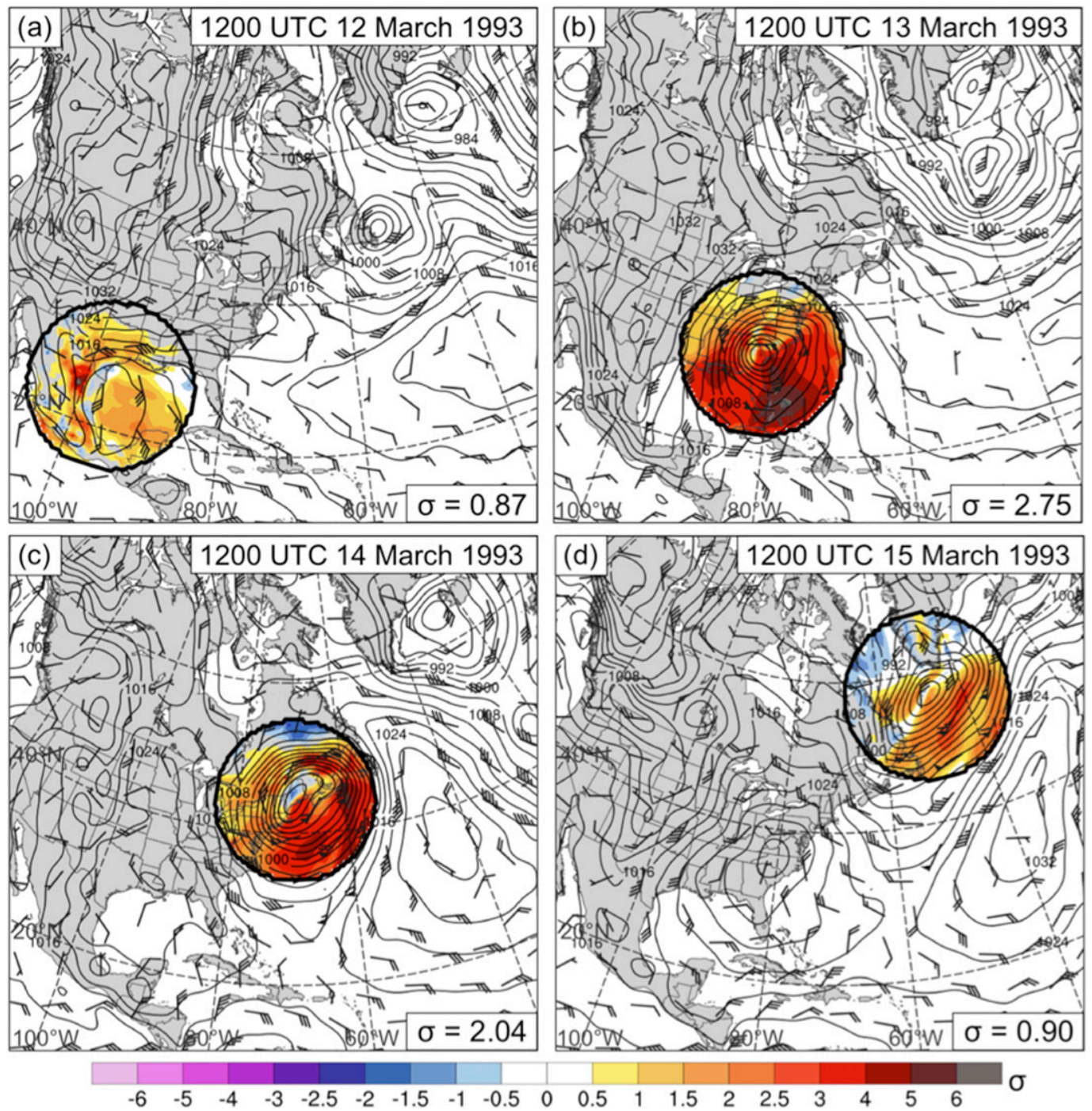

FIG. 3. Analyses showing MSLP (black contours, hPa), 925-hPa winds (flags and barbs, kt), and 925-hPa standardized wind speed anomalies within $1200 \mathrm{~km}$ of SS93 (shaded according to color bar, $\sigma$ ) at (a) 1200 UTC 12 March, (b) 1200 UTC 13 March, (c) 1200 UTC 14 March, and (d) 1200 UTC 15 March 1993. Area-averaged values of 925-hPa standardized wind speed anomalies within $1200 \mathrm{~km}$ of SS93 are shown in the lower-right corner of (a)-(d).

anywhere over central and eastern North America during the cool season, preferentially forming in the lee of the Rocky Mountains and along the east coast of North America. The stronger maximum in the genesis density of ordinary ECs east of the Canadian Rocky Mountains relative to the weaker maximum in the genesis density of ordinary ECs east of the Colorado Rocky Mountains likely reflects the stronger time-mean flow across the Canadian Rocky Mountains during the cool season (not shown). The results of the present study are consistent with the previous results of Zishka and Smith (1980, their Fig. 2b) and Hodges et al. (2011, their Fig. 1b), who also found maxima in the genesis density of North American ECs in the lee of the Rocky
Mountains and along the east coast of North America. In the present study (Fig. 6a), a third, weaker, maximum in the genesis density of ordinary ECs exists over the central United States that was not observed by Zishka and Smith (1980) nor Hodges et al. (2011). Ordinary ECs that form over this region typically result from either 1) the initial development of an EC downstream of an upper-tropospheric trough or 2) the redevelopment of a weak lee cyclone along a lower-tropospheric baroclinic zone over the central United States. The absence of this third, weaker, maximum in the genesis density of North America ECs in the climatologies of Zishka and Smith (1980) and Hodges et al. (2011) may be due to the different time periods and datasets used to construct 


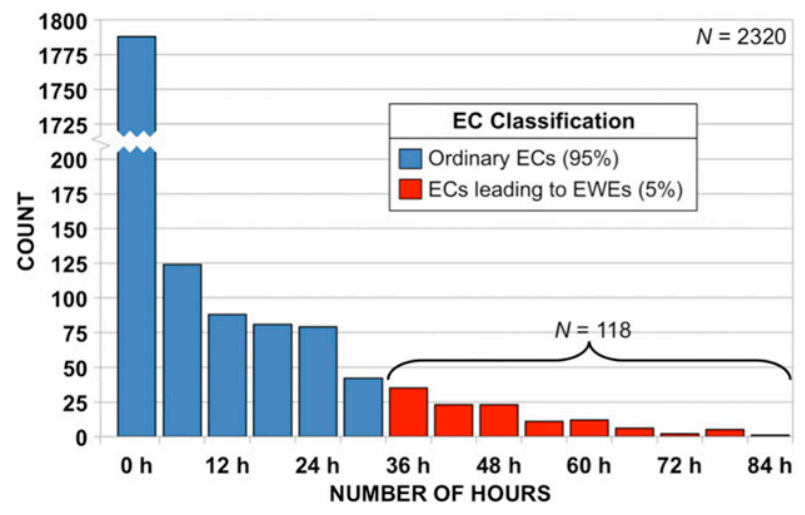

FIG. 4. Frequency distribution of candidate ECs leading to EWEs binned by the number of hours that each EC attained an area-averaged $925-\mathrm{hPa}$ standardized wind speed anomaly $\geq 1 \sigma$. Blue and red regions represent the number of candidate ECs leading to EWEs classified as ordinary ECs and ECs leading to EWEs, respectively.

each climatology, as well as the requirement that ECs form over and traverse the region surrounding central and eastern North America between $t_{0}$ and $t_{0}+48 \mathrm{~h}$ in the present study. Genesis densities in the present study may also differ from those in previous studies due to differences in their definition of the cool season. It is possible that expanding the cool season used in the present study (October-March) to include April and May, when ordinary ECs frequently form in the lee of the Colorado Rocky Mountains (e.g., Whittaker and Horn 1981; Wernli and Schwierz 2006), would result in slightly different genesis densities.

Figure $6 \mathrm{~b}$ reveals that ECs leading to EWEs typically form over the southern portions of the three maxima in the genesis density of ordinary ECs, with ECs leading to EWEs preferentially forming 1) in the lee of the Rocky Mountains, 2) over the south-central United States, and 3) along the east coast of North America. This equatorward shift in the genesis locations of ECs leading to EWEs relative to the genesis locations of ordinary ECs is likely associated with an equatorward shift in the position of the subtropical or polar-front jet, or the phasing of these jets at relatively low latitudes (e.g., Gaza and Bosart 1990; Winters and Martin 2017; Christenson et al. 2017). Stronger horizontal temperature gradients and higher moisture content in the vicinity of the southern Rocky Mountains, Gulf of Mexico, and western North Atlantic during the evolution of ECs leading to EWEs than in the vicinity of the northern Rocky Mountains, Great Plains, and northwestern North Atlantic during the evolution of ordinary ECs may also contribute to the equatorward shift in genesis locations of ECs leading to EWEs relative to those of ordinary ECs. The presence of stronger horizontal temperature gradients and higher moisture content in the vicinity of the southern Rocky Mountains, Gulf of Mexico, and western North Atlantic during the evolution of ECs leading to EWEs likely results in larger contributions from baroclinic and diabatic processes during their life cycles-factors known to contribute to the formation and maintenance of exceptionally strong ECs (e.g., Tracton 1973; Sanders and Gyakum 1980; Roebber 1984; Roebber and Schumann 2011). The contributions from baroclinic and diabatic processes during the life cycles of ordinary ECs and ECs leading to EWEs will be explored in greater detail in a subsequent study.

The presence of three distinct maxima in the genesis density of ECs leading to EWEs (Fig. 6b) allows ECs leading to EWEs to be subjectively categorized as those that form in the lee of the Rocky Mountains $(N=44)$, over the south-central United States $(N=42)$, along the east coast of North America $(N=21)$, or over unclassifiable regions $(N=11)$. Figure 7 depicts the 118

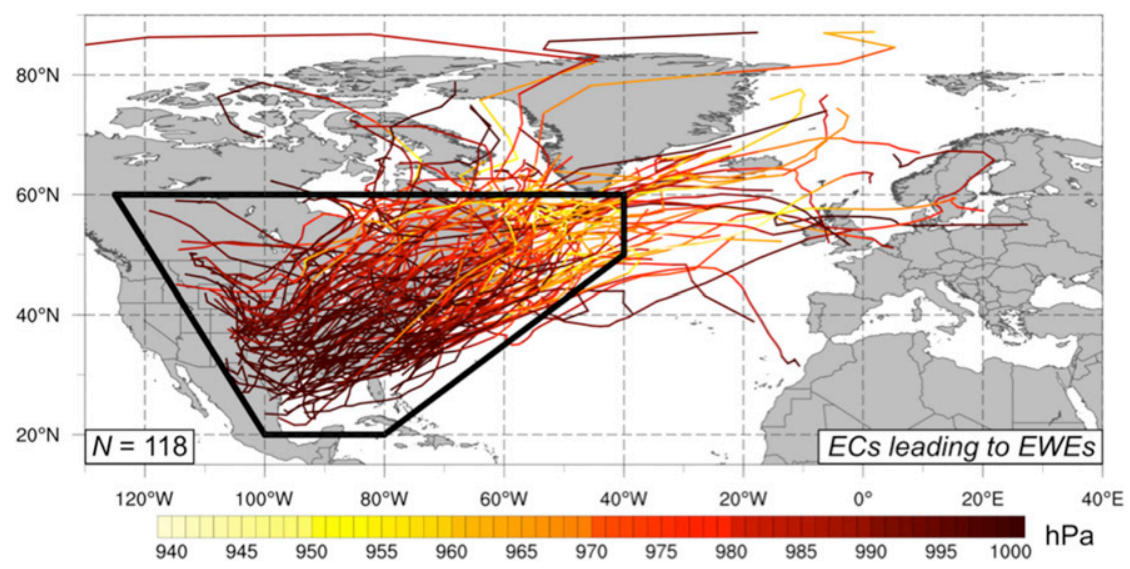

FIG. 5. As in Fig. 2, but for ECs leading to EWEs over central and eastern North America during October-March 1979-2016. 

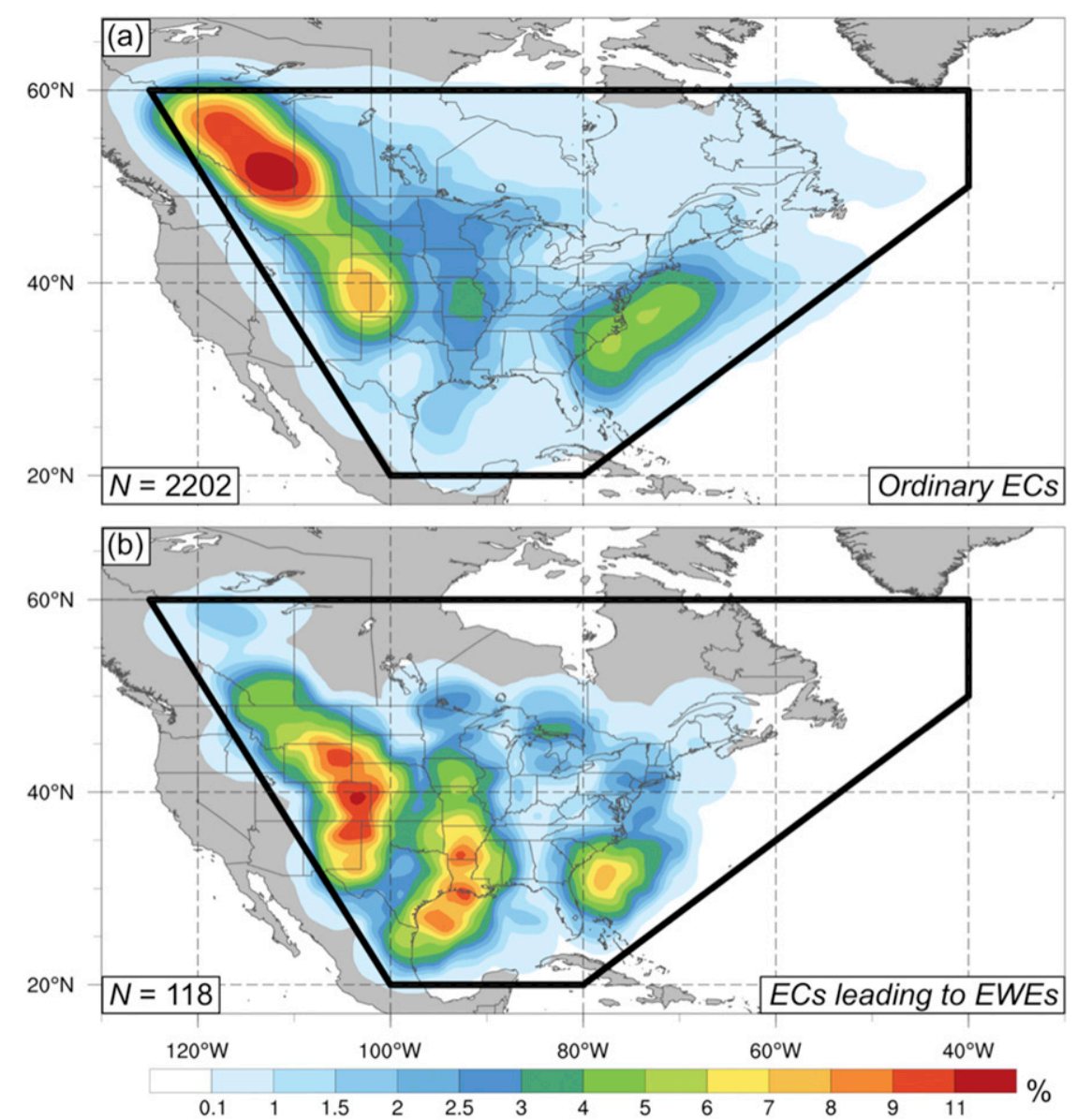

FIG. 6. Genesis density of (a) ordinary ECs and (b) ECs leading to EWEs during OctoberMarch 1979-2016, shaded according to the percentage of ECs forming within $350 \mathrm{~km}$ of a given grid point when normalized by the number of ECs included in each category. The black polygon in (a) and (b) denotes the region over which ordinary ECs and ECs leading to EWEs are required to form and traverse between $t_{0}$ and $t_{0}+48 \mathrm{~h}$.

individual genesis locations of ECs leading to EWEs, shaded according to the region over which EC formation occurs. The distinct separation in the genesis locations of ECs leading to EWEs that form in the lee of the Rocky Mountains and those that form over the south-central United States is likely associated with the confinement of orographic forcing for cyclogenesis to the eastern Rocky Mountains (Chung et al. 1976) and the confinement of moisture from the Gulf of Mexico to the south-central United States (Saucier 1949). The distinct separation in the genesis locations of ECs leading to EWEs that form over the south-central United States and those that form along the east coast of North America is likely associated with the physical separation of the Gulf of Mexico and Gulf Stream, which were identified as separate locations of tropical moisture export into the middle latitudes by Knippertz and Wernli (2010). The occasional displacement of Loop Current eddies into the Gulf of Mexico (e.g., Hurlburt and Thompson 1980; Hamilton et al. 1999; Sturges et al. 2010) could expedite the formation of ECs leading to EWEs over this region by steepening lapse rates and facilitating the development of deep convection, which could serve as a catalyst for EC formation (e.g., Roebber 1989a). The subjective categorization of ECs leading to EWEs based on their location of formation shown in Fig. 7 will be used throughout the remainder of this study to discuss the differences between ECs leading to EWEs that form over different regions.

\section{b. Track density}

Figure 8 compares the track densities of ordinary ECs and ECs leading to EWEs over central and eastern North America during October-March 1979-2016. Figure 8 a reveals that ordinary ECs frequently travel from northwest to southeast across southern Canada, 


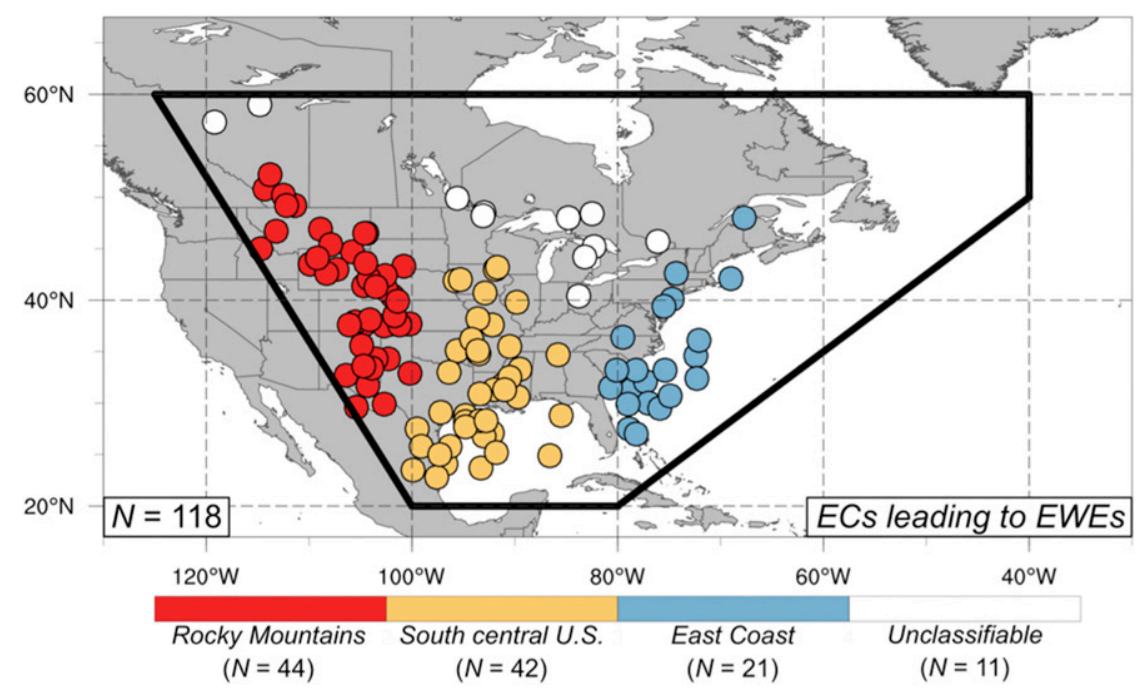

FIG. 7. Genesis locations of ECs leading to EWEs during October-March 1979-2016, shaded according to the region over which EC formation occurs. The black polygon denotes the region over which ECs leading to EWEs are required to form and traverse between $t_{0}$ and $t_{0}+48 \mathrm{~h}$.

as well as from southwest to northeast along the east coast of North America. The results of the present study are consistent with the previous results of Zishka and Smith (1980, their Fig. 2d) and Hodges et al. (2011, their Fig. 1a), who also identified maxima in the track density of North American ECs across southern Canada and along the east coast of North America. Similar to ordinary ECs (Fig. 8a), ECs leading to EWEs (Fig. 8b) frequently travel from southwest to northeast along the east coast of North America. Both ordinary ECs and ECs leading to EWEs benefit from enhanced sensible and latent heat fluxes over this region (e.g., Roebber 1989a,b), as well as more moisture available for condensational heating. In contrast to ordinary ECs, ECs leading to EWEs rarely travel from northwest to southeast across southern Canada in association with lee cyclogenesis along the southern Canadian Rocky Mountains. Instead, ECs leading to EWEs frequently travel from southwest to northeast across the central United States from the Colorado Rocky Mountains and from southwest to northeast across the Mississippi Valley from the south-central United States (Fig. 8b). ECs forming over the southcentral United States and traveling from southwest to northeast across the Mississippi Valley have been previously referred to as "Texas-West Gulf cyclones" (Saucier 1949), and have the potential to produce heavy precipitation along the Gulf Coast during the cool season.

ECs leading to EWEs that form over different regions may be associated with different cyclone tracks. The track densities of ECs leading to EWEs that form in the lee of the Rocky Mountains, over the south-central United States, along the east coast of North America, and over unclassifiable regions are shown in Fig. 9. Figure 9a reveals that ECs leading to EWEs that form in the lee of the Rocky Mountains typically travel from northwest to southeast along the eastern edge of the Colorado Rocky Mountains early in their life cycle before turning to the northeast and traversing the western Great Lakes. As opposed to ordinary ECs forming in the lee of the Canadian Rocky Mountains (Fig. 8a), ECs leading to EWEs forming in the lee of the Colorado Rocky Mountains (Fig. 9a) are located far enough south to potentially tap into moisture from the Gulf of Mexico, enhancing diabatic processes during their life cycles. ECs leading to EWEs that form over the southcentral United States typically travel from southwest to northeast over the southeast United States before traversing the east coast of North America (Fig. 9b). A subset of ECs leading to EWEs that form over the south-central United States also travel from southwest to northeast over the Mississippi Valley and the eastern Great Lakes. ECs leading to EWEs that form along the east coast of North America typically traverse the east coast of North America and Canadian Maritimes during their life cycle (Fig. 9c). ECs leading to EWEs that form over unclassifiable regions exhibit the typical track of Alberta clippers (e.g., Thomas and Martin 2007, their Fig. 1), traveling from northwest to southeast over the Great Lakes region before turning poleward in the vicinity of the east coast of North America (Fig. 9d). The majority of Alberta clippers remain relatively weak as they traverse central and eastern Canada, 

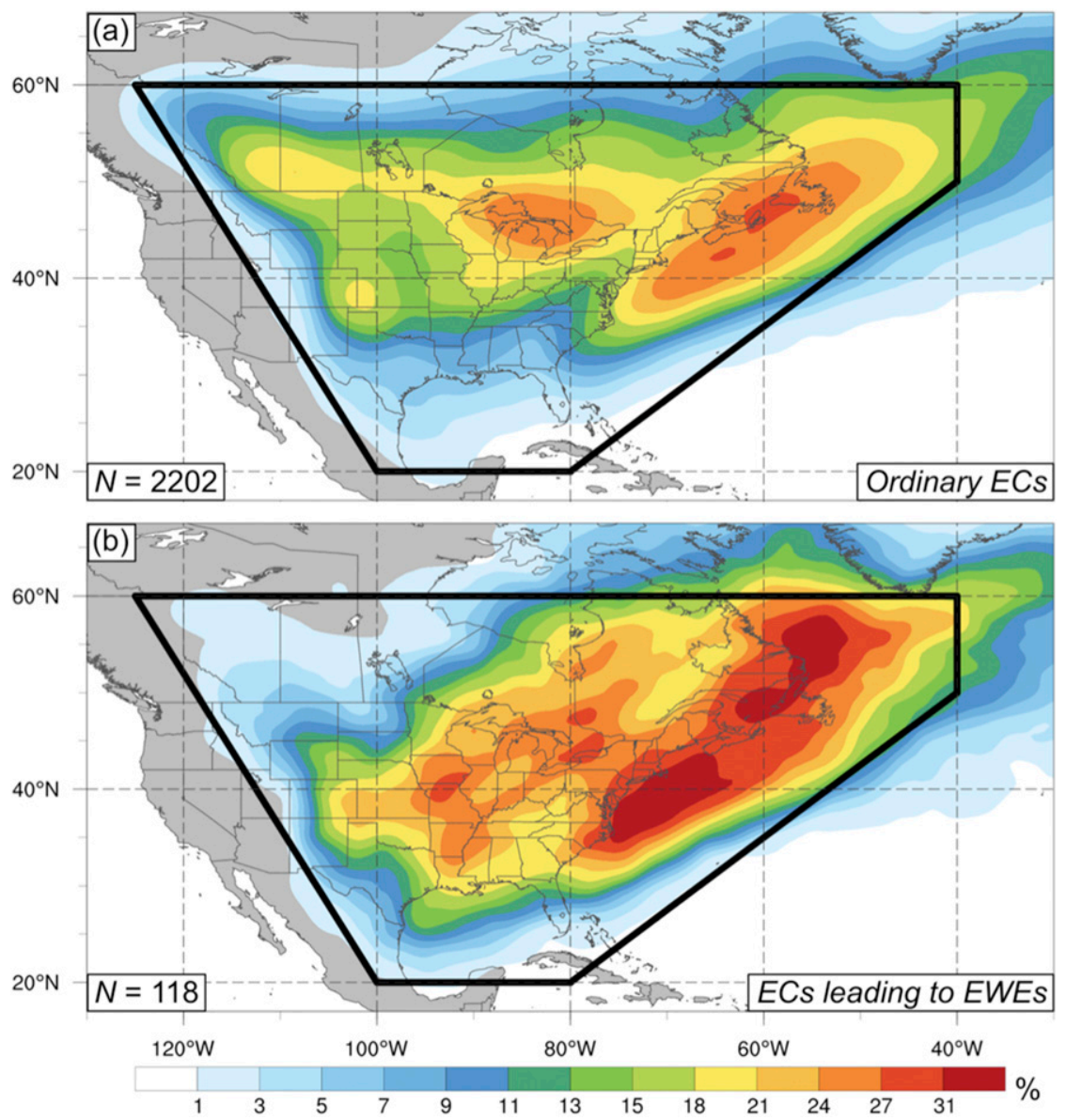

FIG. 8. Track density of (a) ordinary ECs and (b) ECs leading to EWEs during OctoberMarch 1979-2016, shaded according to the percentage of ECs passing within $350 \mathrm{~km}$ of a given grid point when normalized by the number of ECs included in each category. The black polygon in (a) and (b) denotes the region over which ordinary ECs and ECs leading to EWEs are required to form and traverse between $t_{0}$ and $t_{0}+48 \mathrm{~h}$.

only attaining characteristics of ECs leading to EWEs as they approach the region of strong horizontal temperature gradients and high moisture content along the east coast of North America (not shown).

\section{c. Intraseasonal variability}

Figure 10 illustrates the intraseasonal variability associated with the formation of ordinary ECs and ECs leading to EWEs during October-March 1979-2016. Figure 10 reveals that the total number of ordinary ECs and ECs leading to EWEs remains relatively uniform throughout the cool season, with ECs forming most frequently in October and January and least frequently in November and March. The results of the present study are similar to those of Whittaker and Horn (1981) and Changnon et al. (1995), who also document relatively uniform numbers of North American
ECs throughout the cool season. Figure 10 also reveals that, despite ordinary ECs forming most frequently in October and January and the least frequently in November and March, ECs leading to EWEs form most frequently during November and March and the least frequently in October and January. The frequent formation of ECs leading to EWEs in November and March is likely related to the seasonal alignment of baroclinic and diabatic forcings associated with the formation and maintenance of strong ECs (e.g., Tracton 1973; Sanders and Gyakum 1980; Roebber 1984, 1989a,b). The infrequent formation of ECs leading to EWEs in October is likely associated with the presence of relatively weak baroclinic forcing over central and eastern North America at the beginning of the cool season. The infrequent formation of ECs leading to EWEs in January is likely associated with reduced moisture available for condensational heating during the peak of 

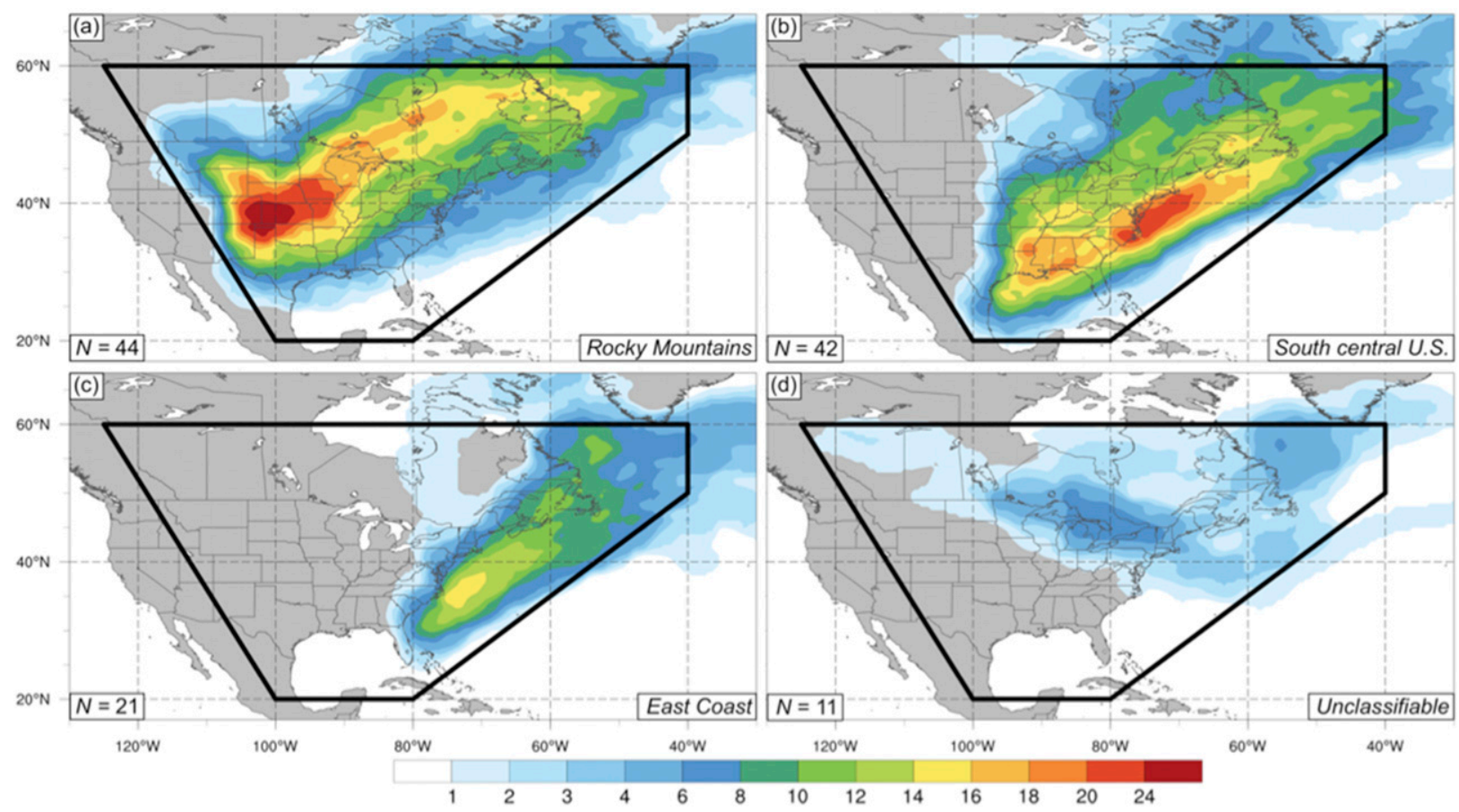

FIG. 9. Track density of ECs leading to EWEs that form (a) in the lee of the Rocky Mountains, (b) over the south-central United States, (c) along the east coast of North America, and (d) over unclassifiable regions during October-March 1979-2016, shaded according to the number of ECs leading to EWEs passing within $350 \mathrm{~km}$ of a given grid point. The black polygon in (a)-(d) denotes the region over which ECs leading to EWEs are required to form and traverse between $t_{0}$ and $t_{0}+48 \mathrm{~h}$.

the cool season (Chang 2001), as well as the suppression of the formation and maintenance of strong ECs by enhanced static stability over often snowcovered continental interiors.

Figure 11 provides a closer examination of the intraseasonal variability associated with the formation of ECs leading to EWEs during October-March 19792016, with ECs leading to EWEs shaded according to the number of ECs that form in the lee of the Rocky Mountains, over the south-central United States, along the east coast of North America, and over unclassifiable regions. In addition to emphasizing the intraseasonal variability associated with ECs leading to EWEs, Fig. 11 reveals the intraseasonal variability associated with ECs leading to EWEs that form over different regions. ECs leading to EWEs that form in the lee of the Rocky Mountains and over the south-central United States develop most frequently in November, February, and March, when baroclinic and diabatic forcings associated with their formation and maintenance are relatively strong. ECs leading to EWEs that form along the east coast of North America develop most frequently in November and December, when the semipermanent baroclinic zone created by the warm waters of the Gulf Stream and relatively cold continental air moving off the eastern side of North America becomes increasingly pronounced and diabatic forcings are still relatively strong. ECs leading to EWEs that form along the east coast of North America also develop frequently in March (e.g., SS93), when baroclinic and diabatic forcings begin to increase again along the east coast of North America. The ECs leading to EWEs that form over unclassifiable regions develop most frequently in October. Many of the ECs leading to EWEs that form over

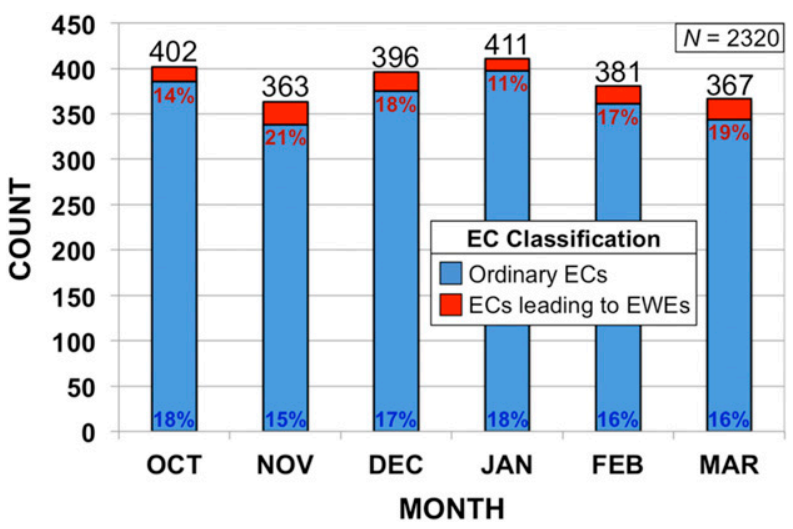

FIG. 10. Frequency distribution of the formation of ordinary ECs (blue) and ECs leading to EWEs (red) during 1979-2016 binned by month (October-March). The percentages of ordinary ECs and ECs leading to EWEs forming during a given month are written in dark blue and dark red, respectively, in each column. 

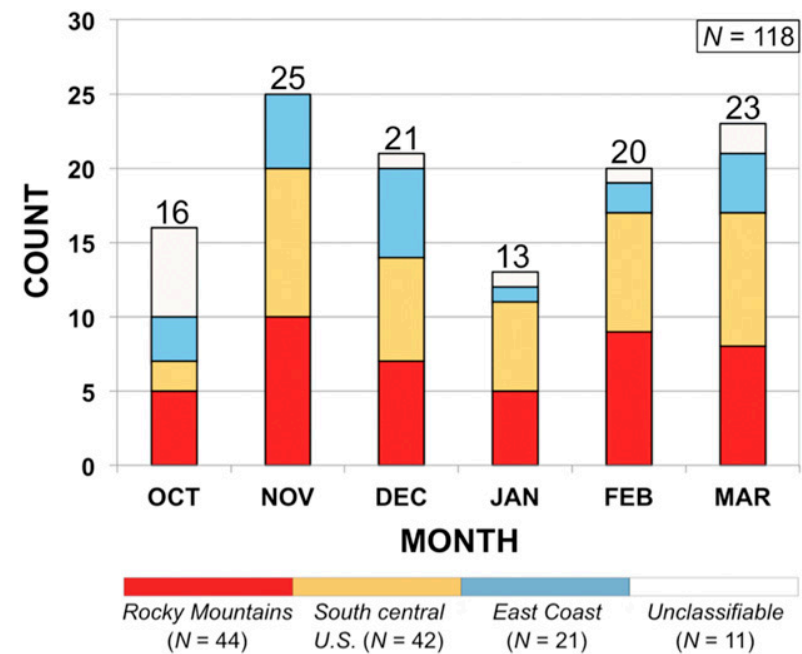

FIG. 11. Frequency distribution of the formation of ECs leading to EWEs during 1979-2016 binned by month (October-March) and shaded according to the region over which EC formation occurs.

unclassifiable regions develop near the Great Lakes (Fig. 7), likely in association with sensible and latent heat fluxes from the Great Lakes when they are warmer than the overlying cool air (e.g., Petterssen and Calabrese 1959; Weiss and Sousounis 1999).

\section{d. Teleconnections}

Previous studies have established the importance of the states of the Pacific-North American (PNA) pattern and North Atlantic Oscillation (NAO) in determining the location and frequency of North American ECs (e.g., Wallace and Gutzler 1981; Barnston and Livezey 1987; Angel and Isard 1998; Isard et al. 2000; Archambault et al. 2008; Grise et al. 2013). In a previous study, Isard et al. (2000) concluded that the frequency of North American ECs was not determined by the state of the PNA at the time of cyclogenesis. An examination of daily PNA indices (CPC 2017a) valid at $t_{0}$ for ECs leading to EWEs (Fig. 12) reveals comparable results, with ECs leading to EWEs forming with similar frequency when the PNA index is negative $(<-0.5 \sigma)$ and positive $(>0.5 \sigma)$. Figure 12 also reveals that ECs leading to EWEs form statistically significantly more frequently when the PNA index is neutral $(-0.5$ to $0.5 \sigma)$ than when the PNA index is negative or positive, indicating than a neutral PNA state does not inhibit the formation of ECs leading to EWEs. The $90 \%$ confidence interval for the number of ECs leading to EWEs included in each PNA state was determined using bootstrap random resampling tests (e.g., Wilks 2006, section 5.3.4). These bootstrap random resampling tests were used to construct new climatologies of ECs leading to EWEs, equal in size to the original climatology

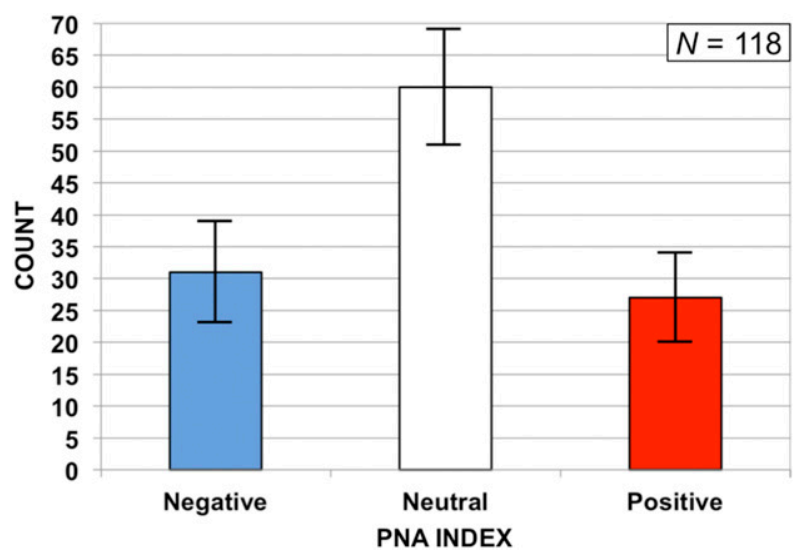

FIG. 12. Number of ECs leading to EWEs that form when the PNA index is negative $(<-0.5 \sigma)$, neutral $(-0.5$ to $0.5 \sigma)$, and positive $(>0.5 \sigma)$ at $t_{0}$. The $90 \%$ confidence interval for each bin is shown using a black line segment. The $90 \%$ confidence interval for each bin was constructed using bootstrap resampling tests described in section $3 \mathrm{~d}$.

( $N=118)$, by randomly drawing a new set of ECs leading to EWEs with replacement from the original climatology. PNA indices associated with ECs leading to EWEs included in each new climatology were binned according to PNA state. A total of 10000 iterations of the bootstrap random resampling test were used to determine the $90 \%$ confidence interval.

Previous studies have established that North American ECs are more likely to form in the lee of the Rocky Mountains when the PNA index is negative and over the southern United States when the PNA index is positive (e.g., Isard et al. 2000; Grise et al. 2013). Similar results are indicated west of the Mississippi River in Fig. 13 of the present study, which illustrates the genesis locations of ECs leading to EWEs over central and eastern North America shaded according to the value of the PNA index at $t_{0}$. Figure 13 reveals that ECs leading to EWEs form more frequently in the lee of the U.S. Rocky Mountains and over the upper Midwest when the PNA index is negative, and form more frequently in the lee of the Sierra Madre Oriental and over the south-central United States when the PNA index is positive. These formation locations are consistent with the synopticscale structure of the North Pacific jet and downstream flow pattern over North America in different PNA states. A negative PNA index is indicative of a retracted North Pacific jet, as well as an upper-tropospheric trough and jet streak over western Canada and the western United States (not shown). The presence of an upper-tropospheric trough and jet streak over western Canada and the western United States suggests the potential for ECs leading to EWEs to form downstream in the lee of the U.S. Rocky Mountains over the 


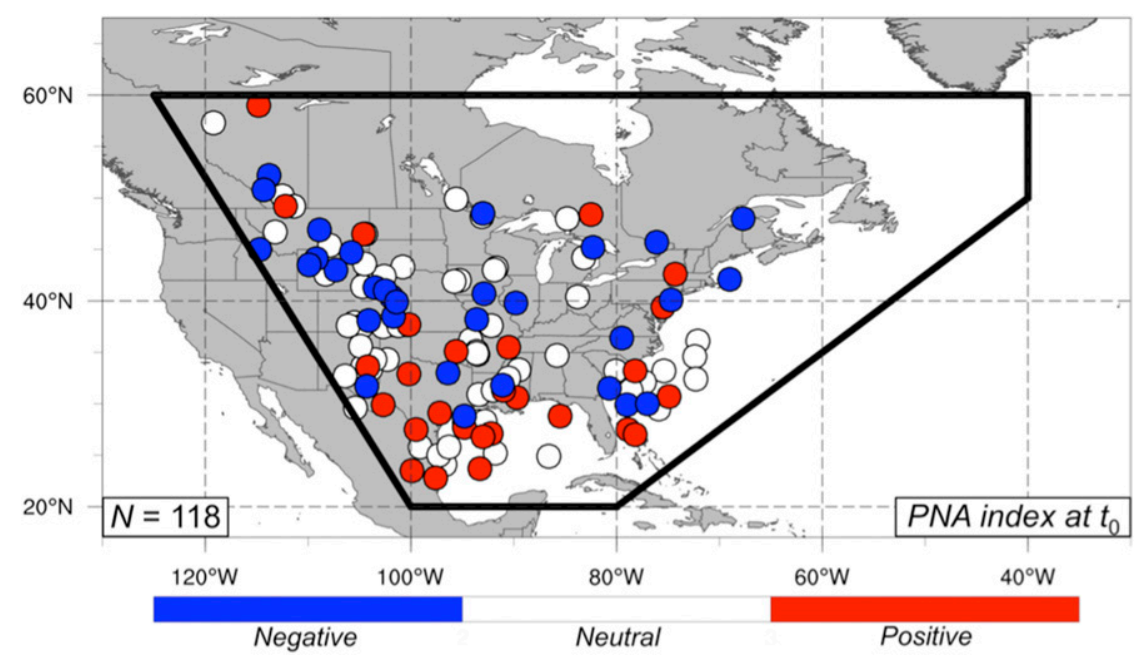

FIG. 13. Genesis locations of ECs leading to EWEs during October-March 1979-2016, shaded according to the value of the PNA index at $t_{0}$. The black polygon denotes the region over which ECs leading to EWEs are required to form and traverse between $t_{0}$ and $t_{0}+48 \mathrm{~h}$.

upper Midwest. A positive PNA index is indicative of an elongated North Pacific jet, as well as an uppertropospheric trough and jet streak over the southwest United States and northern Mexico (not shown). The presence of an upper-tropospheric trough and jet streak over the southwest United States and northern Mexico suggests the potential for ECs leading to EWEs to form downstream in the lee of the Sierra Madre Oriental and over the south-central United States. ECs leading to EWEs that form along the east coast of North America do not appear to develop in any preferred PNA state, possibly due to the distance of these ECs from the main regions used to calculate the PNA index (e.g., Archambault et al. 2008, their Fig. 1).

If the value of the PNA index at $t_{0}$ can influence the genesis locations of ECs leading to EWEs, it is possible that differences in the value of the PNA index at $t_{0}$ may be associated with subsequent track differences in ECs leading to EWEs. Figure 14 illustrates these track differences, separating the track densities of ECs leading to EWEs by the state of the PNA at $t_{0}$. Figure 14a reveals that ECs leading to EWEs that form when the PNA index is negative frequently travel from the Colorado Rocky Mountains over the Great Lakes and from the east coast of the United States over eastern Canada in the left exit region of an upper-tropospheric jet streak located over the central United States (not shown). The results of the present study are consistent with the previous results of Grise et al. (2013, their Fig. 5), who document an increase in North American EC tracks over the Great Lakes and eastern Canada when the PNA index is negative relative to when the PNA index is positive. Unlike ECs leading to EWEs that form when the PNA index is negative (Fig. 14a), ECs leading to EWEs that form when the PNA index is positive (Fig. 14b) frequently traverse the southeast United States and east coast of North America in the left exit region of an upper-tropospheric jet streak located over the southeast United States (not shown). These results are also consistent with the previous results of Grise et al. (2013, their Fig. 5), who document an increase in North American EC tracks over the southeast United States and along the east coast of North America when the PNA index is positive relative to when the PNA index is negative.

In addition to being partially determined by the state of the PNA, the frequency and location of ECs leading to EWEs over central and eastern North America may be partially determined by the state of the NAO. An examination of daily NAO indices (CPC 2017b) valid at $t_{0}$ (Fig. 15) reveals that ECs leading to EWEs form statistically significantly less frequently when the NAO index is negative $(<-0.5 \sigma)$ than when the NAO index is neutral $(-0.5$ to $0.5 \sigma)$ or positive $(>0.5 \sigma)$. Figure 15 also reveals that ECs leading to EWEs form most frequently when the NAO index is neutral, but not statistically significantly more frequently than when the NAO index is positive. Figure 16 illustrates that the state of the NAO does not appear to determine the genesis locations of ECs leading to EWEs, with ECs leading to EWEs forming in the lee of the Rocky Mountains, over the south-central United States, and along the east coast of North America in association with negative, neutral, and positive NAO indices. These results are consistent with the previous results of Grise et al. (2013, their Fig. 3), who found 

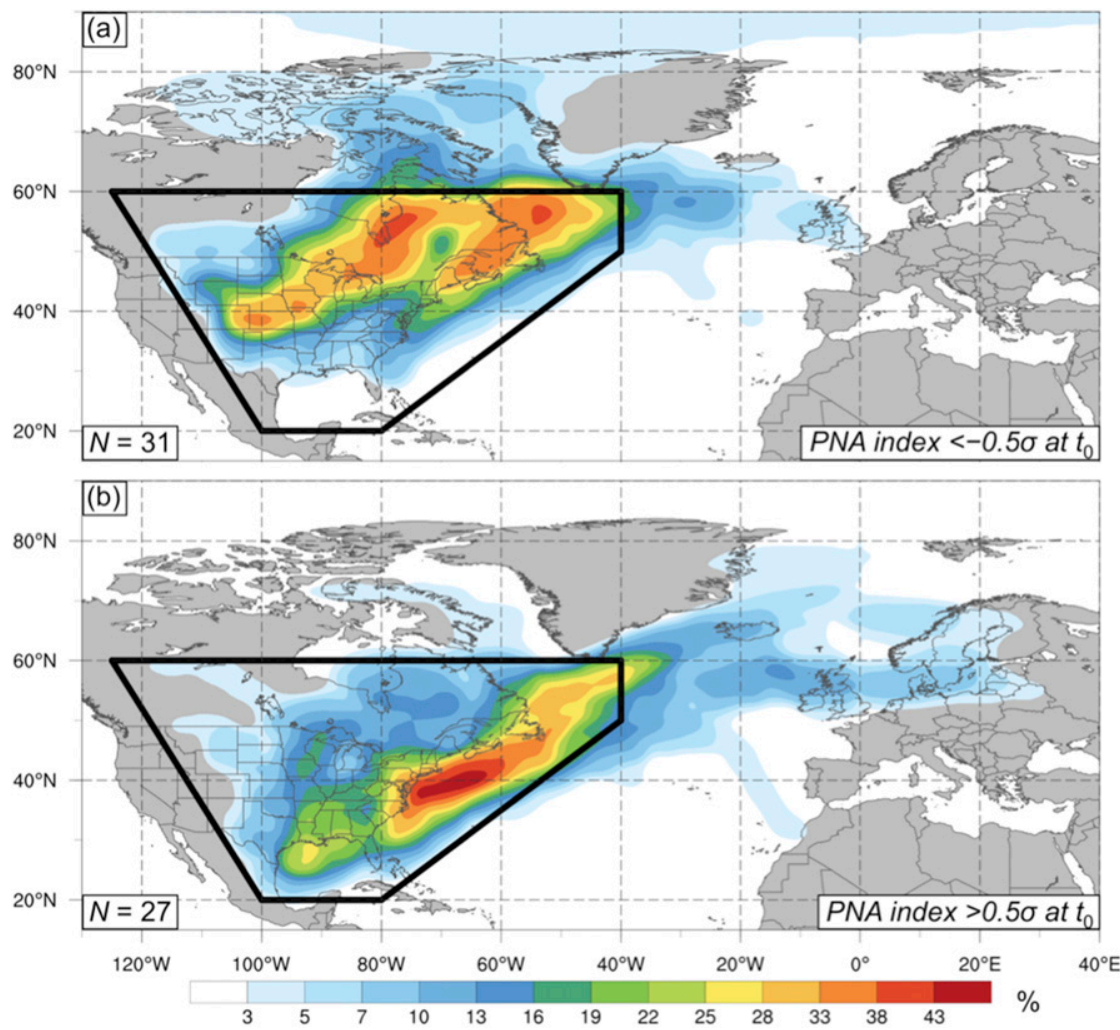

FIG. 14. Track density of ECs leading to EWEs that form when the PNA index is (a) negative $(<-0.5 \sigma)$ or (b) positive $(>0.5 \sigma)$ at $t_{0}$, shaded according to the percentage of ECs passing within $350 \mathrm{~km}$ of a given grid point when normalized by the number of ECs included in each category. The black polygon in (a) and (b) denotes the region over which ECs leading to EWEs are required to form and traverse between $t_{0}$ and $t_{0}+48 \mathrm{~h}$.

little correlation between the genesis locations of North American ECs and the state of the NAO.

Figure 17 illustrates the track density of ECs leading to EWEs over central and eastern North America in the present study, separated by the state of the NAO at $t_{0}$. Figure 17a reveals that ECs leading to EWEs that form when the NAO index is negative frequently traverse the southeast United States and east coast of North America in the right entrance region of an upper-tropospheric jet streak located over the western North Atlantic (not shown). In contrast to ECs leading to EWEs that form when the NAO index is negative (Fig. 17a), ECs leading to EWEs that form when the NAO index is positive (Fig. 17b) frequently travel from the Colorado Rocky Mountains over the Great Lakes in the left exit region of an upper-tropospheric jet streak located over the western United States (not shown). ECs leading to EWEs that form when the NAO index is positive (Fig. 17b) also frequently travel from the east coast of the United States over eastern Canada in the right entrance region of an upper-tropospheric jet streak located over the northwestern
North Atlantic (not shown). These tracks and uppertropospheric jet streak configurations are consistent with the synoptic-scale structure of the North Atlantic jet and upper-tropospheric flow pattern over central and eastern North America in different NAO states. A negative NAO index is indicative of a retracted and equatorward-shifted North Atlantic jet, consistent with ECs leading to EWEs frequently traversing the southeast United States and east coast of North America. The results of the present study are consistent with the previous results of Grise et al. (2013, their Fig. 3), who document an increase in North American EC tracks over the southeast United States and east coast of North America when the NAO index is negative relative to when the NAO index is positive. A positive NAO index is indicative of an elongated and poleward-shifted North Atlantic jet, consistent with ECs leading to EWEs frequently traversing the Great Lakes and eastern Canada. These results are also consistent with the previous results of Grise et al. (2013, their Fig. 3), who document an increase in North American EC tracks north of the Great Lakes and near the southern 


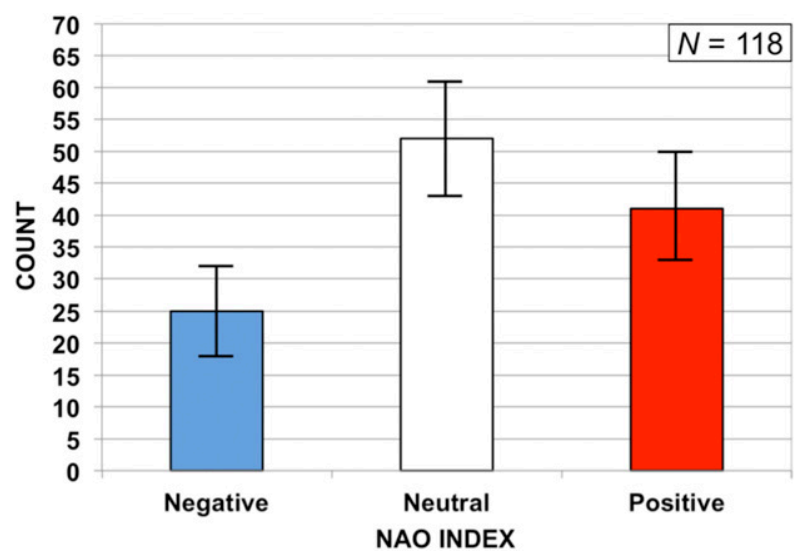

FIG. 15. Number of ECs leading to EWEs that form when the NAO index is negative $(<-0.5 \sigma)$, neutral $(-0.5$ to $0.5 \sigma)$, and positive $(>0.5 \sigma)$ at $t_{0}$. The $90 \%$ confidence interval for each bin is shown using a black line segment. The $90 \%$ confidence interval for each bin was constructed using bootstrap resampling tests described in section $3 \mathrm{~d}$.

tip of Greenland when the NAO index is positive relative to when the NAO index is negative.

\section{Summary and future work}

Particularly strong ECs forming over and traversing densely populated regions of central and eastern North America have the potential to lead to EWEs (i.e., highimpact weather events that are societally disruptive, geographically widespread, exceptionally prolonged, and climatologically infrequent). The EC climatology constructed in the present study differs from the previous EC climatologies listed in Table 1 by identifying
ECs leading to EWEs in terms of the magnitude, areal extent, and duration of their $925-\mathrm{hPa}$ standardized wind speed anomalies and separating them from ordinary ECs. The October-March 1979-2016 climatology of ECs leading to EWEs over central and eastern North America constructed in the present study allows for the genesis locations, tracks, and frequencies of ECs leading to EWEs to be compared with those of ordinary ECs forming over and traversing the same region. This comparison provides insight into the climatological differences between these two categories of ECs and the basis for future studies investigating processes associated with their formation and maintenance.

The results of the present study reveal that ECs leading to EWEs typically form 1) in the lee of the Rocky Mountains, 2) over the south-central United States, and 3) along the east coast of North America, at latitudes equatorward of the typical genesis locations of ordinary ECs. This equatorward shift in the typical genesis locations of ECs leading to EWEs is likely associated with an equatorward shift in the position of the subtropical or polar-front jet, or the phasing of these jets at relatively low latitudes (e.g., Gaza and Bosart 1990; Winters and Martin 2017; Christenson et al. 2017). Stronger horizontal temperature gradients and higher moisture content located at relatively low latitudes during the evolution of ECs leading to EWEs than at relatively high latitudes during the evolution of ordinary ECs may also contribute to the equatorward shift in genesis locations of ECs leading to EWEs relative to those of ordinary ECs. The presence of stronger horizontal temperature gradients and higher moisture content during the evolution of ECs leading to EWEs likely

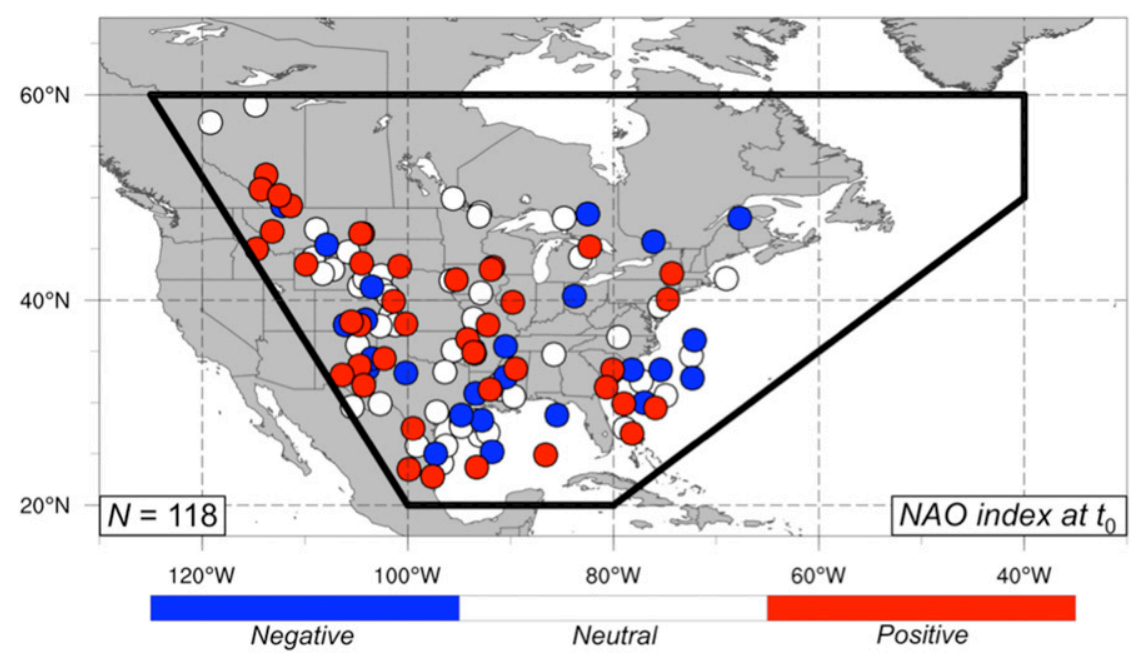

FIG. 16. Genesis locations of ECs leading to EWEs during October-March 1979-2016, shaded according to the value of the NAO index at $t_{0}$. The black polygon denotes the region over which ECs leading to EWEs are required to form and traverse between $t_{0}$ and $t_{0}+48 \mathrm{~h}$. 

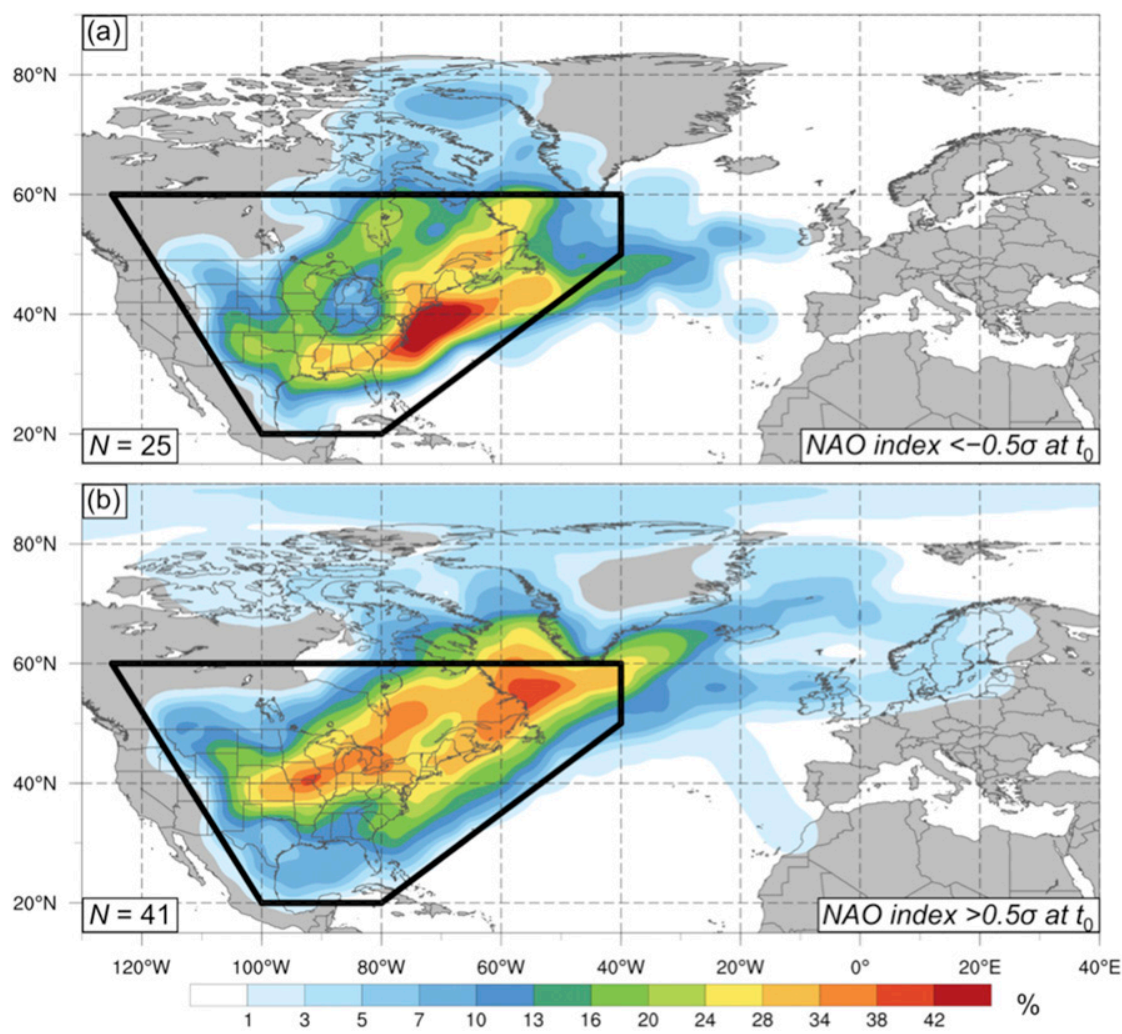

FIG. 17. Track density of ECs leading to EWEs that form when the NAO index is (a) negative $(<-0.5 \sigma)$ or $(\mathrm{b})$ positive $(>0.5 \sigma)$ at $t_{0}$, shaded according to the percentage of ECs passing within $350 \mathrm{~km}$ of a given grid point when normalized by the number of ECs included in each category. The black polygon in (a) and (b) denotes the region over which ECs leading to EWEs are required to form and traverse between $t_{0}$ and $t_{0}+48 \mathrm{~h}$.

results in larger contributions from baroclinic and diabatic processes during their life cycles. The importance of larger contributions from baroclinic and diabatic processes during the life cycles of ECs leading to EWEs is also illustrated by their intraseasonal variability. ECs leading to EWEs form most frequently in November and March (i.e., the shoulder seasons), when the seasonal alignment of baroclinic and diabatic forcings is maximized. ECs leading to EWEs form least frequently in October and January, likely due to the presence of relatively weak baroclinic forcing at the beginning of the cool season and reduced moisture available for condensational heating during the peak of the cool season, respectively. In contrast to ECs leading to EWEs, ordinary ECs exhibit relatively little intraseasonal variability, forming slightly more frequently during the peak of the cool season when baroclinic forcings are the most pronounced and the subtropical and polar-front jets are located over North America (e.g., Manney et al. 2014; Christenson et al. 2017).

The results of the present study also reveal that ECs leading to EWEs forming over different regions are associated with different intraseasonal variability and cyclone tracks. ECs leading to EWEs that form in the lee of the Rocky Mountains and over the south-central United States develop most frequently in November, February, and March, when baroclinic and diabatic forcings associated with their formation and maintenance are relatively strong. ECs leading to EWEs that form in the lee of the Rocky Mountains typically travel from northwest to southeast along the eastern edge of the Colorado Rocky Mountains early in their life cycle before turning to the northeast and traversing the western Great Lakes, consistent with ECs forming in the lee of the Colorado Rocky Mountains in previous climatologies (e.g., Hodges et al. 2011, their Fig. 1a). ECs leading to EWEs that form over the south-central United States typically travel from southwest to northeast over the southeast United States before traversing the east coast of North America, consistent with the tracks of previously documented "Texas-West Gulf cyclones" (Saucier 1949). ECs leading to EWEs that form along and traverse the east coast of North America exhibit different intraseasonal variability than those 
forming over and traversing other regions, developing most frequently in November and December when the semipermanent baroclinic zone created by the warm waters of the Gulf Stream and relatively cold continental air moving off the eastern side of North America becomes increasingly pronounced and diabatic forcings are relatively strong over the western North Atlantic (e.g., Sanders and Gyakum 1980; Roebber 1984). ECs leading to EWEs that form along and traverse the east coast of North America also frequently form in March, when baroclinic and diabatic forcings begin to increase again along the east coast of North America (e.g., Mather et al. 1964, their Table 2). Few ECs leading to EWEs exhibit the typical northwest to southeast track of Alberta clippers (e.g., Thomas and Martin 2007, their Fig. 1), which comprise a large subset of ordinary ECs, likely due to the absence of strong horizontal temperature gradients and high moisture content in the vicinity of southern Canada during the cool season.

The present study demonstrates that, much like North American ECs in previous studies (e.g., Isard et al. 2000), the location and frequency of ECs leading to EWEs over central and eastern North America are partially determined by the state of the PNA and NAO at the time of EC formation $\left(t_{0}\right)$. ECs leading to EWEs form statistically significantly more frequently when the PNA index is neutral than when it is negative or positive, indicating that a neutral PNA state (in which the North Pacific jet is neither elongated nor retracted) does not inhibit the formation of ECs leading to EWEs. ECs leading to EWEs also show little preference for formation between negative or positive PNA states. ECs leading to EWEs form more frequently in the lee of the U.S. Rocky Mountains and over the upper Midwest when the PNA index is negative and in the lee of the Sierra Madre Oriental and over the south-central United States when the PNA index is positive. In addition to influencing the genesis locations of ECs leading to EWEs, the value of the PNA index at $t_{0}$ may influence the subsequent track of ECs leading to EWEs over central and eastern North America. ECs leading to EWEs that form when the PNA index is negative frequently travel from the Colorado Rocky Mountains over the Great Lakes in the left exit region of an uppertropospheric jet streak located over the central United States, whereas ECs leading to EWEs that form when the PNA index is positive frequently traverse the southeast United States and east coast of North America in the left exit region of an upper-tropospheric jet streak located over the southeast United States.

The present study also demonstrates that ECs leading to EWEs form statistically significantly less frequently when the NAO index is negative than when it is neutral or positive, suggesting that a weaker and retracted North Atlantic jet may be less conducive to the formation of ECs leading to EWEs over central and eastern North America than a stronger and elongated North Atlantic jet. Little preference for formation between neutral or positive NAO states is shown in the present study. The state of the NAO at $t_{0}$ does not appear to determine the genesis locations of ECs leading to EWEs, consistent with the results of previous EC studies (e.g., Grise et al. 2013, their Fig. 3). However, the state of the NAO at $t_{0}$ does appear to be associated with the subsequent track of ECs leading to EWEs over central and eastern North America. ECs leading to EWEs that form when the NAO index is negative frequently traverse the southeast United States and east coast of North America in the right entrance region of an uppertropospheric jet streak located over the western North Atlantic. ECs leading to EWEs that form when the NAO index is positive frequently travel from the east coast of the United States over eastern Canada in the right entrance region of an upper-tropospheric jet streak located over the northwestern North Atlantic. ECs leading to EWEs that form when the NAO index is positive also frequently travel from the Colorado Rocky Mountains over the Great Lakes in the left exit region of an upper-tropospheric jet streak located over the western United States.

The October-March 1979-2016 climatology of ECs leading to EWEs over central and eastern North America constructed in the present study provides the foundation on which to investigate baroclinic and diabatic processes associated with the formation and maintenance of ECs leading to EWEs. Based on their equatorward-shifted tracks and seasonal peak in frequency during the shoulder seasons, the authors hypothesize that ECs leading to EWEs are associated with contributions from baroclinic and diabatic processes that are considerably larger than those associated with ordinary ECs during their life cycles. In addition to baroclinic and diabatic processes, barotropic processes (i.e., the conversion of kinetic energy of the midlatitude jet into the kinetic energy of an EC) can also contribute to the formation and maintenance of ordinary ECs and ECs leading to EWEs. Metrics representing baroclinic, diabatic, and barotropic processes will be formulated in a subsequent study and calculated throughout the life cycle of individual ordinary ECs and ECs leading to EWEs. An examination of these metrics could provide further insight into baroclinic, diabatic, and barotropic processes associated with the formation and maintenance of ordinary ECs and ECs leading to EWEs over central and eastern North America, as well as over other regions. 
Acknowledgments. The authors are grateful to Paul Roebber (University of Wisconsin-Milwaukee), as well as two anonymous reviewers, whose specific and thoughtful suggestions improved this paper. The authors thank Brian Colle (Stony Brook University) for providing the Northern Hemisphere cyclone tracks that made this research possible. The authors also thank Kevin Biernat (University at Albany), Christopher Davis (National Center for Atmospheric Research), Andrea Lang (University at Albany), Benjamin Moore (Cooperative Institute for Research in Environmental Sciences), Kyle Pallozzi (National Weather Service), Philippe Papin (U.S. Naval Research Laboratory), Rebecca Steeves (University of Oklahoma Cooperative Institute for Mesoscale Meteorological Studies), Ryan Torn (University at Albany), Matthew Vaughan (University at Albany), and Andrew Winters (University at Albany) for helpful discussions and research assistance. This research was funded by NSF Grants AGS-1355960 and AGS-1656406.

\section{REFERENCES}

Alfonso, A. P., and L. R. Naranjo, 1996: The 13 March 1993 severe squall line over western Cuba. Wea. Forecasting, 11, 89102, https://doi.org/10.1175/1520-0434(1996)011<0089: TMSSLO $>2.0 . \mathrm{CO} ; 2$.

Angel, J. R., and S. Isard, 1998: The frequency and intensity of Great Lake cyclones. J. Climate, 11, 61-71, https://doi.org/ 10.1175/1520-0442(1998)011<0061:TFAIOG > 2.0.CO;2.

Archambault, H. M., L. F. Bosart, D. Keyser, and A. R. Aiyyer, 2008: Influence of large-scale low regimes on cool-season precipitation in the northeastern United States. Mon. Wea. Rev., 136, 2945-2963, https://doi.org/10.1175/2007MWR2308.1.

Atlas, R. A., 1987: The role of ocean fluxes and initial data on the numerical prediction of an intense coastal storm. Dyn. Atmos. Oceans, 10, 359-388, https://doi.org/10.1016/0377-0265(87)90025-X.

Bannon, P. R., 1992: A model of Rocky Mountain lee cyclogenesis. J. Atmos. Sci., 49, 1510-1522, https://doi.org/10.1175/15200469(1992)049<1510:AMORML>2.0.CO;2.

Barnston, A. G., and R. E. Livezey, 1987: Classification, seasonality and persistence of low-frequency atmospheric circulation patterns. Mon. Wea. Rev., 115, 1083-1126, https://doi.org/ 10.1175/1520-0493(1987)115<1083:CSAPOL > 2.0.CO;2.

Bierly, G. D., and J. A. Harrington Jr., 1995: A climatology of transition season Colorado cyclones: 1961-1990. J. Climate, 8, 853-863, https://doi.org/10.1175/1520-0442(1995)008<0853: ACOTSC $>2.0 . \mathrm{CO} ; 2$.

Bosart, L. F., G. J. Hakim, K. R. Tyle, M. A. Bedrick, W. E. Bracken, M. J. Dickinson, and D. M. Schultz, 1996: Largescale antecedent conditions associated with the 12-14 March 1993 cyclone ("superstorm '93") over eastern North America Mon. Wea. Rev., 124, 1865-1891, https://doi.org/10.1175/15200493(1996)124<1865:LSACAW >2.0.CO;2.

Bowie, E. H., and R. H. Weightman, 1914: Types of storms of the United States and their average movements. Mon. Wea. Rev., 42 (Suppl. 1), 3-37.

Brammer, A., and C. D. Thorncroft, 2015: Variability and evolution of African easterly wave structures and their relationship with tropical cyclogenesis over the eastern Atlantic.
Mon. Wea. Rev., 143, 4975-4995, https://doi.org/10.1175/ MWR-D-15-0106.1.

Brennan, F. E., and P. J. Smith, 1978: The climatology of cyclones and anticyclones in the upper Mississippi and Ohio River valleys and Great Lakes region, 1950-1974. Proc. Ind. Acad. Sci., 87, 391-402.

Bullock, T. A., and J. R. Gyakum, 1993: A diagnostic study of cyclogenesis in the western North Pacific Ocean. Mon. Wea. Rev., 121, 65-75, https://doi.org/10.1175/1520-0493(1993)121<0065: ADSOCI $>2.0 . \mathrm{CO} ; 2$.

Chang, E. K. M., 2001: GCM and observational diagnoses of the seasonal and interannual variations of the Pacific storm track during the cool season. J. Atmos. Sci., 58, 1784-1800, https://doi.org/10.1175/1520-0469(2001)058<1784: GAODOT $>2.0 . \mathrm{CO} ; 2$.

Changnon, D., J. J. Noel, and L. H. Maze, 1995: Determining cyclone frequencies using equal-area circles. Mon. Wea. Rev., 123, 2285-2294, https://doi.org/10.1175/1520-0493(1995)123<2285: DCFUEA $>2.0 . \mathrm{CO} ; 2$.

, C. Merinsky, and M. Lawson, 2008: Climatology of surface cyclone tracks associated with large central and eastern U.S. snowstorms, 1950-2000. Mon. Wea. Rev., 136, 3193-3202, https://doi.org/10.1175/2008MWR2324.1.

Christenson, C. E., J. E. Martin, and Z. J. Handlos, 2017: A synoptic climatology of Northern Hemisphere, cold season polar and subtropical jet superposition events. J. Climate, 30, 72317246, https://doi.org/10.1175/JCLI-D-16-0565.1.

Chung, Y.-S., K. D. Hage, and E. R. Reinelt, 1976: On lee cyclogenesis and airflow in the Canadian Rocky Mountains and the East Asian mountains. Mon. Wea. Rev., 104, 879-891, https://doi.org/ 10.1175/1520-0493(1976)104<0879:OLCAAI > 2.0.CO;2.

Colle, B. A., Z. Zhang, K. A. Lombardo, E. Chang, P. Liu, and M. Zhang, 2013: Historical evaluation and future prediction of eastern North American and western Atlantic extratropical cyclones in the CMIP5 models during the cool season. J. Climate, 26, 6882-6903, https://doi.org/10.1175/ JCLI-D-12-00498.1.

Colucci, S. J., 1976: Winter cyclone frequencies over the eastern United States and adjacent western Atlantic, 1964-1973. Bull. Amer. Meteor. Soc., 57, 548-553, https://doi.org/10.1175/ 1520-0477(1976)057<0548:WCFOTE $>2.0 . C O ; 2$.

CPC, 2017a: Normalized daily PNA indices. Accessed 14 October 2017, ftp://ftp.cpc.ncep.noaa.gov/cwlinks/norm.daily.pna.index. b500101.current.ascii.

2017b: Normalized daily NAO indices. Accessed 14 October 2017, ftp://ftp.cpc.ncep.noaa.gov/cwlinks/norm.daily.nao.index. b500101.current.ascii.

Dacre, H. F., M. K. Hawcroft, M. A. Stringer, and K. I. Hodges, 2012: An extratropical cyclone atlas: A tool for illustrating cyclone structure and evolution characteristics. Bull. Amer. Meteor. Soc., 93, 1497-1502, https://doi.org/10.1175/ BAMS-D-11-00164.1.

Davis, C. A., 1997: The modification of baroclinic waves by the Rocky Mountains. J. Atmos. Sci., 54, 848-868, https://doi.org/ 10.1175/1520-0469(1997)054<0848:TMOBWB > 2.0.CO;2. , and K. A. Emanuel, 1988: Observational evidence for the influence of surface heat fluxes on maritime cyclogenesis. Mon. Wea. Rev., 116, 2649-2659, https://doi.org/10.1175/15200493(1988)116<2649:OEFTIO>2.0.CO;2.

Dickinson, M. J., L. F. Bosart, W. E. Bracken, G. J. Hakim, D. M. Schultz, M. A. Bedrick, and K. R. Tyle, 1997: The March 1993 superstorm cyclogenesis: Incipient phase synoptic- and convective-scale flow interaction and model 
performance. Mon. Wea. Rev., 125, 3041-3072, https://doi.org/ 10.1175/1520-0493(1997)125<3041:TMSCIP>2.0.CO;2.

Eichler, T. P., and J. Gottschalck, 2013: Interannual variability of Northern Hemisphere storm tracks in coarse-gridded datasets. Adv. Meteor., 2013, 545463, https://doi.org/10.1155/ 2013/545463.

— ability of North American extratropical cyclone activity. J. Climate, 19, 2076-2093, https://doi.org/10.1175/JCLI3725.1.

Gaza, R. S., and L. F. Bosart, 1990: Trough-merger characteristics over North America. Wea. Forecasting, 5, 314-331, https://doi.org/ 10.1175/1520-0434(1990)005<0314:TMCONA > 2.0.CO;2.

Grise, K. M., S.-W. Son, and J. R. Gyakum, 2013: Intraseasonal and interannual variability in North American storm tracks and its relationship to equatorial Pacific variability. Mon. Wea. Rev., 141, 3610-3625, https://doi.org/10.1175/MWR-D-12-00322.1.

Gyakum, J. R., 1983a: On the evolution of the $Q E I I$ storm. I: Synoptic aspects. Mon. Wea. Rev., 111, 1137-1155, https://doi.org/ 10.1175/1520-0493(1983)111<1137:OTEOTI>2.0.CO;2.

, 1983b: On the evolution of the $Q E I I$ storm. II: Dynamic and thermodynamic structure. Mon. Wea. Rev., 111, 1156-1173, https:// doi.org/10.1175/1520-0493(1983)111<1156:OTEOTI >2.0.CO;2.

__ , and R. E. Danielson, 2000: Analyses of meteorological precursors to ordinary and explosive cyclogenesis in the western North Pacific. Mon. Wea. Rev., 128, 851-863, https://doi.org/ 10.1175/1520-0493(2000)128<0851:AOMPTO>2.0.CO;2.

—, P. J. Roebber, and T. A. Bullock, 1992: The role of antecedent surface vorticity development as a conditioning process in explosive cyclone intensification. Mon. Wea. Rev., 120, 1465-1489, https://doi.org/10.1175/1520-0493(1992)120<1465: TROASV $>2.0 . \mathrm{CO} ; 2$.

Hakim, G. J., L. F. Bosart, and D. Keyser, 1995: The Ohio Valley wavemerger cyclogenesis event of 25-26 January 1978. Part I: Multiscale case study. Mon. Wea. Rev., 123, 2663-2692, https://doi.org/ 10.1175/1520-0493(1995)123<2663:TOVWMC >2.0.CO;2.

__ D. Keyser, and L. F. Bosart, 1996: The Ohio valley wavemerger cyclogenesis event of 25-26 January 1978. Part II: Diagnosis using quasigeostrophic potential vorticity inversion. Mon. Wea. Rev., 124, 2176-2205, https://doi.org/10.1175/15200493(1996)124<2176:TOVWMC > 2.0.CO;2.

Hamilton, P., G. S. Fargion, and D. C. Biggs, 1999: Loop Current eddy paths in the western Gulf of Mexico. J. Phys. Oceanogr., 29, 1180-1207, https://doi.org/10.1175/1520-0485(1999)029<1180: LCEPIT $>2.0 . \mathrm{CO} ; 2$.

Hayden, B. P., 1981: Secular variation in Atlantic coast extratropical cyclones. Mon. Wea. Rev., 109, 159-167, https://doi.org/10.1175/ 1520-0493(1981)109<0159:SVIACE > 2.0.CO;2.

Hirsch, M. E., A. T. DeGaetano, and S. J. Colucci, 2001: An East Coast winter storm climatology. J. Climate, 14, 882-899, https://doi.org/ 10.1175/1520-0442(2001)014<0882:AECWSC > 2.0.CO;2.

Hodges, K. I., 1994: A general method for tracking analysis and its application to meteorological data. Mon. Wea. Rev., 122, 2573-2586, https://doi.org/10.1175/1520-0493(1994)122<2573: AGMFTA $>2.0 . \mathrm{CO} ; 2$.

- 1995: Feature tracking on the unit sphere. Mon. Wea. Rev., 123, 3458-3465, https://doi.org/10.1175/1520-0493(1995)123<3458: FTOTUS $>2.0 . \mathrm{CO} ; 2$.

— , R. W. Lee, and L. Bengtsson, 2011: A comparison of extratropical cyclones in recent reanalyses ERA-Interim, NASA MERRA, NCEP CFSR, and JRA-25. J. Climate, 24, 48884906, https://doi.org/10.1175/2011JCLI4097.1.

Hoskins, B. J., and K. I. Hodges, 2002: New perspectives on the Northern Hemisphere winter storm tracks. J. Atmos. Sci., 59,
1041-1061, https://doi.org/10.1175/1520-0469(2002)059<1041: NPOTNH $>2.0 . \mathrm{CO} ; 2$.

Hosler, C. L., and L. A. Gamage, 1956: Cyclone frequencies in the United States for the period 1905 to 1954. Mon. Wea. Rev., 84 388-390, https://doi.org/10.1175/1520-0493(1956)084<0388: CFITUS $>2.0 . \mathrm{CO} ; 2$.

Huo, Z., D.-L. Zhang, J. Gyakum, and A. Staniforth, 1995: A diagnostic analysis of the superstorm of March 1993. Mon. Wea. Rev., 123, 1740-1761, https://doi.org/10.1175/1520-0493(1995) $123<1740$ :ADAOTS $>2.0$.CO;2.

Hurlburt, H. E., and J. D. Thompson, 1980: A numerical study of Loop Current intrusions and eddy shedding. J. Phys. Oceanogr., 10, 1611-1651, https://doi.org/10.1175/1520-0485(1980) $010<1611$ :ANSOLC $>2.0$. CO;2.

Hurley, J. C., 1954: Statistics on the movement and deepening of cyclones in the Middle West. Mon. Wea. Rev., 82, 116-122, https://doi.org/10.1175/1520-0493(1954)082<0116: SOTMAD $>2.0 . \mathrm{CO} ; 2$.

Hutchinson, T. A., 1995: An analysis of NMC's nested grid model forecasts of Alberta clippers. Wea. Forecasting, 10, 632-641, https://doi.org/10.1175/1520-0434(1995)010<0632: AAONNG $>2.0 . \mathrm{CO} ; 2$.

Iacopelli, A. J., and J. A. Knox, 2001: Mesoscale dynamics of the record-breaking 10 November 1998 mid-latitude cyclone: A satellite-based case study. Natl. Wea. Dig., 25, 33-42.

Isard, S., J. Angel, and G. VanDyke, 2000: Zones of origin for Great Lakes cyclones in North America, 1899-1996. Mon. Wea. Rev., 128, 474-485, https://doi.org/10.1175/1520-0493 (2000)128<0474:ZOOFGL > 2.0.CO;2.

Klein, W. H., 1957: Principal tracks and mean frequencies of cyclones and anticyclones in the Northern Hemisphere. Research Paper No. 40, U.S. Weather Bureau, Washington, DC, 60 pp.

Knapp, K. R., M. C. Kruk, D. H. Levinson, H. J. Diamond, and C. J. Neumann, 2010: The International Best Track Archive for Climate Stewardship (IBTrACS): Unifying tropical cyclone data. Bull. Amer. Meteor. Soc., 91, 363-376, https://doi.org/ 10.1175/2009BAMS2755.1.

Knippertz, P., and H. Wernli, 2010: A Lagrangian climatology of tropical moisture exports to the Northern Hemispheric extratropics. J. Climate, 23, 987-1003, https://doi.org/10.1175/ 2009JCLI3333.1.

Kocin, P. J., and L. W. Uccellini, 2004: A snowfall impact scale derived from Northeast storm snowfall distributions. Bull. Amer. Meteor. Soc., 85, 177-194, https://journals.ametsoc.org/doi/ 10.1175/BAMS-85-2-177.

- , P. N. Schumacher, R. F. Morales Jr., and L. W. Uccellini, 1995: Overview of the 12-14 March 1993 superstorm. Bull. Amer. Meteor. Soc., 76, 165-182, https://doi.org/10.1175/15200477(1995)076<0165:OOTMS>2.0.CO;2.

Kuo, Y.-H., R. J. Reed, and Y. Liu, 1996: The ERICA IOP 5 storm. Part III: Mesoscale cyclogenesis and precipitation parameterization. Mon. Wea. Rev., 124, 1409-1434, https://doi.org/ 10.1175/1520-0493(1996)124<1409:TEISPI>2.0.CO;2.

Mailier, P. J., D. B. Stephenson, C. A. Ferro, and K. I. Hodges, 2006: Serial clustering of extratropical cyclones. Mon. Wea. Rev., 134, 2224-2240, https://doi.org/10.1175/MWR3160.1.

Manney, G. L., M. I. Hegglin, W. H. Daffer, M. J. Schwartz, M. L. Santee, and S. Pawson, 2014: Climatology of upper tropospheric-lower stratospheric (UTLS) jets and tropopauses in MERRA. J. Climate, 27, 3248-3271, https://doi.org/10.1175/ JCLI-D-13-00243.1.

Mather, J. R., H. Adams, and G. A. Yoshioka, 1964: Coastal storms of the eastern United States. J. Appl. Meteor., 3, 
693-706, https://doi.org/10.1175/1520-0450(1964)003<0693: CSOTEU $>2.0 . \mathrm{CO} ; 2$.

McTaggart-Cowan, R., J. R. Gyakum, and R. W. Moore, 2017: The baroclinic moisture flux. Mon. Wea. Rev., 145, 25-47, https:// doi.org/10.1175/MWR-D-16-0153.1.

Miller, J. E., 1946: Cyclogenesis in the Atlantic coastal region of the United States. J. Meteor., 3, 31-44, https://doi.org/10.1175/ 1520-0469(1946)003<0031:CITACR $>2.0 . C O ; 2$.

NCEI, 2018: Regional snowfall index: The Northeast snowfall impact scale. NOAA/NCEI, accessed 10 October 2018, https:// www.ncdc.noaa.gov/snow-and-ice/rsi/nesis.

Palmén, E., and C. W. Newton, 1969: Atmospheric Circulation Systems. Academic Press, 603 pp.

Petterssen, S., 1956: Weather Analysis and Forecasting. McGrawHill, 428 pp.

— to warming of the air by the Great Lakes in winter. J. Meteor., 16, 646-652, https://doi.org/10.1175/1520-0469(1959)016<0646: OSWIDT $>2.0 . \mathrm{CO} ; 2$.

Reed, R. J., and A. J. Simmons, 1991: Numerical simulation of an explosively deepening cyclone over the North Atlantic that was unaffected by concurrent surface energy fluxes. Wea. Forecasting, 6, 117-122, https://doi.org/10.1175/1520-0434(1991) 006<0117:NSOAED $>2.0$. CO;2.

,,-- M. D. Albright, and P. Undén, 1988: The role of latent heat release in explosive cyclogenesis: Three examples based on ECMWF operational forecasts. Wea. Forecasting, 3, 217-229, https://doi.org/10.1175/1520-0434(1988)003<0217: TROLHR $>2.0 . \mathrm{CO} ; 2$.

_- M. T. Stoelinga, and Y.-H. Kuo, 1992: A model-aided study of the origin and evolution of the anomalously high potential vorticity in the inner region of a rapidly deepening marine cyclone. Mon. Wea. Rev., 120, 893-913, https://doi.org/ 10.1175/1520-0493(1992)120<0893:AMASOT>2.0.CO;2.

_ , G. A. Grell, and Y.-H. Kuo, 1993a: The ERICA IOP 5 storm. Part I: Analysis and simulation. Mon. Wea. Rev., 121, 1577-1594, https://doi.org/10.1175/1520-0493(1993)121<1577: TEISPI $>2.0 . \mathrm{CO} ; 2$.

,-- , and $\longrightarrow, 1993 \mathrm{~b}$ : The ERICA IOP 5 storm. Part II: Sensitivity tests and further diagnosis based on model output. Mon. Wea. Rev., 121, 1595-1612, https://doi.org/10.1175/ 1520-0493(1993)121<1595:TEISPI > 2.0.CO;2.

Reitan, C. H., 1974: Frequencies of cyclones and cyclogenesis over North America, 1951-1970. Mon. Wea. Rev., 102, 861-868, https://doi.org/10.1175/1520-0493(1974)102<0861: FOCACF $>2.0 . \mathrm{CO} ; 2$.

Roebber, P. J., 1984: Statistical analysis and updated climatology of explosive cyclones. Mon. Wea. Rev., 112, 15771589, https://doi.org/10.1175/1520-0493(1984)112<1577: SAAUCO $>2.0 . \mathrm{CO} ; 2$

_ 1989a: The role of surface heat and moisture fluxes associated with large-scale ocean current meanders in maritime cyclogenesis. Mon. Wea. Rev., 117, 1676-1694, https://doi.org/ 10.1175/1520-0493(1989)117<1676:TROSHA > 2.0.CO;2.

_ 1989b: On the statistical analysis of cyclone deepening rates. Mon. Wea. Rev., 117, 2293-2298, https://doi.org/10.1175/15200493(1989) $117<2293$ :OTSAOC > 2.0.CO;2.

_ 1993: A diagnostic case study of self-development as an antecedent conditioning process in explosive cyclogenesis. Mon. Wea. Rev., 121, 976-1006, https://doi.org/10.1175/1520-0493 (1993)121<0976:ADCSOS>2.0.CO;2.

__, and M. R. Schumann, 2011: Physical processes governing the rapid deepening tail of maritime cyclogenesis.
Mon. Wea. Rev., 139, 2776-2789, https://doi.org/10.1175/ MWR-D-10-05002.1.

Rudeva, I., and S. K. Gulev, 2011: Composite analysis of North Atlantic extratropical cyclones in NCEP-NCAR reanalysis data. Mon. Wea. Rev., 139, 1419-1446, https://doi.org/10.1175/ 2010MWR3294.1.

Saha, S., and Coauthors, 2010: The NCEP Climate Forecast System Reanalysis. Bull. Amer. Meteor. Soc., 91, 1015-1057, https:// doi.org/10.1175/2010BAMS3001.1.

Salmon, E. M., and P. J. Smith, 1980: A synoptic analysis of the 2526 January 1978 blizzard cyclone in the central United States. Bull. Amer. Meteor. Soc., 61, 453-460, https://doi.org/10.1175/ 1520-0477(1980)061<0453:FOFASA > 2.0.CO;2.

Sanders, F., and J. R. Gyakum, 1980: Synoptic-dynamic climatology of the "bomb." Mon. Wea. Rev., 108, 1589-1606, https://doi.org/ 10.1175/1520-0493(1980)108<1589:SDCOT>2.0.CO;2.

Saucier, W. J., 1949: Texas-west Gulf cyclones. Mon. Wea. Rev., 77, 219-231, https://doi.org/10.1175/1520-0493(1949)077<0219:TGC>2.0.CO;2.

SPC, 1999: March 12-13, 1993 derecho: "The 'storm of the century' or 'superstorm' derecho." NOAA/SPC, accessed 10 October 2018, https://www.spc.noaa.gov/misc/AbtDerechos/casepages/ mar12-131993page.htm.

Sturges, W., N. G. Hoffmann, and R. R. Leben, 2010: A trigger mechanism for Loop Current ring separations. J. Phys. Oceanogr., 40, 900-913, https://doi.org/10.1175/2009JPO4245.1.

Thomas, B. C., and J. E. Martin, 2007: A synoptic climatology and composite analysis of the Alberta clipper. Wea. Forecasting, 22, 315-333, https://doi.org/10.1175/WAF982.1.

Tilinina, N., S. K. Gulev, I. Rudeva, and P. Koltermann, 2013: Comparing cyclone life cycle characteristics and their interannual variability in different reanalyses. J. Climate, 26 , 6419-6438, https://doi.org/10.1175/JCLI-D-12-00777.1.

Tracton, M. S., 1973: The role of cumulus convection in the development of extratropical cyclones. Mon. Wea. Rev., 101, 573-593, https://doi.org/10.1175/1520-0493(1973)101<0573: TROCCI $>2.3 . \mathrm{CO} ; 2$.

Uccellini, L. W., P. J. Kocin, R. A. Petersen, C. H. Wash, and K. F. Brill, 1984: The Presidents' Day cyclone of 18-19 February 1979: Synoptic overview and analysis of the subtropical jet streak influencing the pre-cyclogenetic period. Mon. Wea. Rev., 112, 31-55, https://doi.org/10.1175/1520-0493(1984) 112<0031:TPDCOF $>2.0$. CO 2 .

, D. Keyser, K. F. Brill, and C. H. Wash, 1985: The Presidents' Day cyclone of 18-19 February 1979: Influence of upstream trough amplification and associated tropopause folding on rapid cyclogenesis. Mon. Wea. Rev., 113, 962-988, https://doi.org/ 10.1175/1520-0493(1985)113<0962:TPDCOF>2.0.CO;2.

, R. A. Petersen, K. F. Brill, P. J. Kocin, and J. J. Tuccillo, 1987: Synergistic interactions between an upper-level jet streak and diabatic processes that influence the development of a lowlevel jet and a secondary coastal cyclone. Mon. Wea. Rev., 115, 2227-2261, https://doi.org/10.1175/1520-0493(1987)115<2227: SIBAUL $>2.0 . \mathrm{CO} ; 2$

— , P. J. Kocin, R. S. Schneider, P. M. Stokols, and R. A. Dorr, 1995: Forecasting the 12-14 March 1993 superstorm. Bull. Amer. Meteor. Soc., 76, 183-199, https://doi.org/10.1175/15200477(1995)076<0183:FTMS > 2.0.CO;2.

Wallace, J. M., and D. S. Gutzler, 1981: Teleconnections in the geopotential height field during the Northern Hemisphere winter. Mon. Wea. Rev., 109, 784-812, https://doi.org/10.1175/ 1520-0493(1981)109<0784:TITGHF>2.0.CO;2.

Weiss, C. C., and P. J. Sousounis, 1999: A climatology of collective lake disturbances. Mon. Wea. Rev., 127, 
565-574, https://doi.org/10.1175/1520-0493(1999)127<0565: ACOCLD $>2.0 . C O ; 2$.

Wernli, H., and C. Schwierz, 2006: Surface cyclones in the ERA-40 dataset (1958-2001). Part I: Novel identification method and global climatology. J. Atmos. Sci., 63, 2486-2507, https://doi.org/ 10.1175/JAS3766.1.

Whittaker, L. M., and L. H. Horn, 1981: Geographical and seasonal distribution of North American cyclogenesis, 1958-1977. Mon. Wea. Rev., 109, 2312-2322, https://doi.org/10.1175/1520-0493 (1981) $109<2312:$ GASDON $>2.0$. CO;2.

Wilks, D. S., 2006: Statistical Methods in the Atmospheric Sciences. 2nd ed. Academic Press, 627 pp.
Winters, A. C., and J. E. Martin, 2017: Diagnosis of a North American polar-subtropical jet superposition employing piecewise potential vorticity inversion. Mon. Wea. Rev., 145, 18531873, https://doi.org/10.1175/MWR-D-16-0262.1.

WPC, 2010: Midwest high wind event. NOAA/WPC, accessed 13 October 2017, http://www.wpc.ncep.noaa.gov/winter_storm_ summaries/event_reviews/2010/Midwest_High_Wind2010.pdf.

Zishka, K. M., and P. J. Smith, 1980: The climatology of cyclones and anticyclones over North America and surrounding ocean environs for January and July, 1950-77. Mon. Wea. Rev., 108, 387-401, https://doi.org/10.1175/1520-0493(1980)108<0387: TCOCAA $>2.0 . \mathrm{CO} ; 2$. 